\title{
El ejercicio de la actividad aseguradora por las empresas de la Economía Social: una revisión crítica de
} la situación en España ${ }^{(*)}$

\section{Insurance Activity by Social Economy Companies: A Critical Review of the Situation in Spain}

\author{
María José Puyalto Franco(**) \\ Universidad de Lleida - España
}

\begin{abstract}
Resumen: Las empresas de la Economía Social constituyen un instrumento jurídico especialmente valioso para el empoderamiento de trabajadores y consumidores en un mercado digital y globalizado y una clara alternativa a las empresas capitalistas. A pesar de que España fue pionera en el reconocimiento jurídico de este sector mediante la publicación de la Ley 5/2011, de 29 de marzo, de Economía social, el principal reproche se dirige a la falta de aplicación de esta norma y, más en concreto, de las medidas contempladas en la Disposición adicional séptima que, entre otras cuestiones, instaba a revisar la normativa necesaria para eliminar las limitaciones de las entidades de la economía social, de forma que estas pudieran operar en cualquier actividad económica sin trabas injustificadas. El legislador español no ha realizado ningún esfuerzo solvente y sistemático para llevar a cabo la citada revisión y, en este trabajo, daremos cuenta de las consecuencias su inacción sobre las empresas de la Economía Social que operan en un sector altamente regulado como es el mercado de seguros.
\end{abstract}

Palabras clave: Economía Social - Sociedades Cooperativas - Sociedades Mutuas Actividad Aseguradora

\begin{abstract}
Social Economy companies constitute not only a particularly valuable legal instrument to empower workers and consumers in a digital and globalised market, but they are also a clear alternative to profit-making companies. Although Spain was a pioneer by recognising this sector in the Law 5/2011, of March 29th, of Social Economy, the main criticism lies in the lack of application of the framework, in general, and the measures of the Seventh Additional Provision, in particular. These measures called for the review of specific legislation in order to remove the limitations to Social Economy entities so that they could operate in any economic activity without any unjustified barrier. However, the Spanish legislator has not made any extra or systematic effort to reach that end. Therefore, this academic work will address the consequences of this inaction concerning the Social Economy companies that operate in a highly regulated sector: the insurance market.
\end{abstract}

Keywords: Social economy - Cooperative Societies - Mutual Societies - Insurance Activity.

$\left(^{*}\right) \quad$ Nota del editor: este artículo fue recibido el 28 de octubre del 2018 y su publicación fue aprobada el 20 de noviembre de 2018.

${ }^{* *}$ Doctora en Derecho y profesora contratada por la Universidad de Lleida (España). Correo electrónico: mjpuyalto@dpriv.udl.cat 


\section{Introducción: La Economía Social en España.}

En la última década, nuestro país ha asistido a un renovado interés por la Economía Social (en adelante, "ES") que dio sus primeros pasos cuando el Gobierno de España designó una Comisión independiente de personas expertas dirigidas por el profesor José Luís Monzón Campos que en octubre de 2009 finalizó los trabajos de elaboración del "Informe para la elaboración de una ley de fomento de la Economía Social". Partiendo del Informe de esta Comisión y de la propuesta de texto articulado elaborado por la Confederación Empresarial Española de Economía Social (CEPES), se procedió a la elaboración de un texto común ${ }^{(1)}$ que contó con el respaldo mayoritario del sector de la Economía Social y que sirvió de base para la redacción de la Ley 5/2011, de 29 de marzo, de Economía Social (en adelante, "LES").

Está norma, pionera en el ámbito internacional(2), tiene como objetivo principal establecer un marco jurídico común para el conjunto de entidades que integran la ES, con pleno respeto a la normativa específica aplicable a cada una de ellas, así como determinar las medidas de fomento a favor de las mismas en consideración a los fines y principios que les son propios. El artículo 2 dispone que la ES hace referencia:

"al conjunto de las actividades económicas y empresariales, que en el ámbito privado llevan a cabo aquellas entidades que, de conformidad con los principios recogidos en el artículo 4, persiguen bien el interés colectivo de sus integrantes, bien el interés general económico o social, o ambos".

Estos principios son los siguientes: (i) Primacía de las personas y del fin social sobre el capital, que se concreta en gestión autónoma y transparente, democrática y participativa, que lleva a priorizar la toma de decisiones más en función de las personas y sus aportaciones de trabajo y servicios prestados a la entidad o en función del fin social, que en relación a sus aportaciones al capital social, (ii) Aplicación de los resultados obtenidos de la actividad económica principalmente en función del trabajo aportado y servicio o actividad realizada por las socias y socios 0 por sus miembros y, en su caso, al fin social objeto de la entidad, (iii) Promoción de la solidaridad interna y con la sociedad que favorezca el compromiso con el desarrollo local, la igualdad de oportunidades entre hombres y mujeres, la cohesión social, la inserción de personas en riesgo de exclusión social, la generación de empleo estable y de calidad, la conciliación de la vida personal, familiar y laboral y la sostenibilidad, (iv) Independencia respecto a los poderes públicos ${ }^{(3)}$.

En cuanto a las entidades que integran la ES, el articulo 5 LES se refiere a las cooperativas, las mutualidades, las fundaciones y las asociaciones que lleven a cabo actividad económica, las sociedades laborales, las empresas de inserción, los centros especiales de empleo, las cofradías de pescadores, y las sociedades agrarias de transformación. A estas entidades, el precepto añade "las entidades singulares creadas por normas específicas ${ }^{(4)}$ que se rijan por los principios establecidos en el artículo $4 \mathrm{y}$ "aquellas entidades que realicen actividad económica y empresarial cuyas reglas de funcionamiento respondan a dichos principios, y que sean incluidas en el catálogo de entidades establecido en el artículo 6 de esta Ley". Esta norma, hace referencia al encargo que el legislador formula al Ministerio de Trabajo e Inmigración (hoy Ministerio de Empleo y Seguridad Social) para que, previo informe del Consejo para el Fomento de la Economía Social, y en coordinación con las Comunidades Autónomas, elabore y mantenga actualizado un catálogo de los diferentes tipos de entidades integrantes de la economía social. Posteriormente y, en virtud de la Ley 31/2015, de 9 de septiembre, por la que se modifica y actualiza la normativa en materia de autoempleo y se adoptan medidas de fomento y promoción del trabajo autónomo y de la Economía Social, se introduce un nuevo párrafo en el artículo 5 LES por el que "se declaran entidades prestadoras de Servicios de Interés Económico General( ${ }^{(5)}$,

(1) Rosalía Alfonso Sánchez, "Algunas consideraciones sobre en torno a la propuesta de Ley "Marco" de Economía Social”, REVESCO, núm. 102, (2010): 7-23. En su trabajo la autora argumenta que (la entonces) propuesta de Ley Marco de Economía Social intentaba materializar todos los aspectos enunciados del Informe Toia partiendo del reconocimiento jurídico de la ES en nuestro Estado vía elaboración de una ley ad hoc.

(2) En la actualidad únicamente tienen normas equiparables a la LES: Francia, México y Portugal.

(3) Estos principios coinciden sustancialmente con los planteados en la Carta de Principios de la Economía Social, promovida por Social Economy Europe, organización representativa a nivel de la UE para la ES que se creó en noviembre de 2000, bajo el nombre de CEP-CMAF. Estos principios son: a) Primacía de las personas y del fin social sobre el capital. b) Satisfacción de las necesidades e intereses de sus miembros y/o la búsqueda del interés general. c) Independencia respecto a los poderes políticos. d) Gestión autónoma y transparente, democrática y participativa, con o sin ánimo de lucro. e) Aplicación de los excedentes o de gran parte de los mismos al objeto social de la entidad y a sus socios, en su caso. f) Compromiso con el desarrollo local, la cohesión social y la sostenibilidad. g) Promover la solidaridad interna y con la sociedad.

(4) La Disposición adicional tercera de la LES establece que la Organización Nacional de Ciegos Españoles (ONCE) es una organización singular de economía social.

(5) Recuérdese que el artículo 2 LES hace referencia al "interés económico general" como criterio para determinar aquellas actividades económicas o empresariales que se integran en el concepto de ES. 
los Centros Especiales de Empleo y las Empresas de Inserción, constituidas y calificadas como tales según su normativa reguladora" asimismo se añade que "podrá extenderse esta declaración a cualesquiera otras entidades de la economía social que tengan por objeto igualmente la inserción laboral de colectivos en riesgo de exclusión, conforme a lo que se establezca reglamentariamente".

El resto de la LES se dedica a cuestiones institucionales, representativas o de fomento, reconociendo que las entidades de la ES pueden constituir asociaciones para la representación y defensa de sus intereses y que éstas puedan agruparse entre si $^{(6)}$; estableciendo los requisitos que deben reunir Confederaciones intersectoriales de ámbito estatal representativas y las condiciones de su participación en los órganos de la Administración General del Estado(7); enumerando los objetivos de la políticas de promoción de la ES por parte de los poderes públicos ${ }^{(8)} \mathrm{y}$, finalmente, regulando el Consejo para el Fomento de la Economía Social que se configura como el órgano asesor y consultivo para las actividades relacionadas con la economía social ${ }^{(9)}$.

Igualmente resulta de interés destacar el contenido de algunas de las Disposiciones adicionales de la LES. Así, la primera de estas Disposiciones insta al Ministerio de Trabajo e Inmigración (hoy Ministerio de Empleo y Seguridad Social) a adoptar las medidas necesarias para garantizar una información estadística de dichas entidades así como de sus organizaciones de representación, periódicamente actualizada y ajustada en su clasificación al catálogo previsto en el artículo 6 LES. La Disposición adicional cuarta exhorta al Gobierno de España para que tenga en cuenta las especiales características de las empresas de la economía social en sus estrategias de mejora de la productividad y la competitividad empresarial. La Disposición adicional quinta ordena al Gobierno que, en el plazo de dos años desde la entrada en vigor de la LES, remita al Congreso de los Diputados un informe en el que se analice y evalúe los efectos y las consecuencias de la aplicación del contenido de la misma. Finalmente, la Disposición adicional séptima insta, ordena al Gobierno aprobar en el plazo de seis meses desde la entrada en vigor de esta Ley, un programa de impulso de las entidades de economía social, con especial atención a las de singular arraigo en su entorno y a las que generen empleo en los sectores más desfavorecidos. Este programa entre otras ha de reflejar las siguientes medidas: (i) Revisar la normativa necesaria para eliminar las limitaciones de las entidades de la economía social, de forma que estas puedan operar en cualquier actividad económica sin trabas injustificadas; (ii) Remitir a las Cortes un proyecto de ley que actualice y revise la Ley 4/1997, de 24 de marzo, de Sociedades Laborales; y (iii) Revisar la normativa de desarrollo de la Ley 38/2003, de 17 de noviembre, General de Subvenciones con el objeto de simplificar los procedimientos regulados en la misma.

Apenas tres meses después de la publicación de la LES, la Comisión de Economía y Hacienda del Congreso de los Diputados aprueba por unanimidad el "Informe sobre economía social"(10). Este Informe fue elaborado por la Subcomisión para el fomento de la economía social constituida en el seno de la citada Comisión a finales del año 2006 con un doble objetivo: por un lado, realizar un análisis de la situación de las entidades de economía social, y por otro, avanzar en la definición de propuestas de reformas normativas necesarias en la legislación estatal en materia fiscal, financiera y laboral aplicable al conjunto de entidades de economía social, con objeto de conseguir un trato fiscal, financiero y laboral favorable. Según se anuncia en la introducción del documento, el Informe se presenta estructurado en tres partes. Una primera, denominada "Constataciones", en la que se trata de recoger las conclusiones de carácter más general que pueden extraerse de las comparecencias de los expertos en la citada Subcomisión. En la segunda, bajo el epígrafe "Directrices Generales", se presentan aquellos criterios y enfoques que pueden ayudar a entender mejor las recomendaciones que se recogen en el tercer apartado. La tercera parte está dedicada a recoger una amplia gama de "Recomendaciones" similares en gran medida a las contenidas en el Informe aprobado por el Parlamento Europeo sobre Economía Social de 26 de enero de 2009 (Informe Toia)(11). Por su interés en esta sede pasaremos seguidamente a comentar algunas de estas recomendaciones.

En primer lugar, se encuentran las sugerencias que exigen una determinada

(6) Artículo 7 LES.

(7) Artículo 7 LES.

(8) Artículo 8 LES.

(9) Artículo 13 LES.

(10) BOCG. Congreso de los Diputados Núm. D-598 de 01/07/2011. La Subcomisión no pudo concluir sus trabajos por el fin de la legislatura y a mediados de 2008 el Grupo Parlamentario Catalán CiU, solicitó la reapertura del órgano. A principios de 2010, la Comisión de Economía y Hacienda del Congreso de los Diputados aprobó por unanimidad la propuesta de CiU. Además de la Subcomisión para el fomento de la economía social, en la Comisión de Economía y Hacienda del Congreso existe otra Subcomisión sobre reestructuración bancaria y recursos propios especialmente activa durante este año 2011.

(11) Resolución del Parlamento Europeo del 19 de febrero de 2009 relativa a la Economía Social (2008/2250(INI)). El informe aprobado por el Parlamento Europeo se conoce con el nombre de su principal promotora, Patrizia Toia, europarlamentaria italiana que pertenece al partido de los Liberales y Demócratas por Europa. En 2013, un nuevo "Informe Toia" sobre la contribución de las cooperativas a la 


\section{El ejercicio de la actividad aseguradora por las empresas de la Economía Social: una revisión crítica de la situación en España}

acción normativa a fin y efecto de lograr el pleno reconocimiento jurídico de la ES tales como: (i) Realizar una identificación legislativa de la ES, mediante un estatuto jurídico de la Economía Social; (ii) Avanzar en la delimitación jurídica de los requisitos que deben cumplir los integrantes de la ES para evitar la banalización de sus rasgos identitarios y la pérdida de su utilidad social. Asimismo, se recomienda la actualización o renovación de las normas y leyes específicas de cada familia de la ES para asegurar que permitan ampliar toda la capacidad competitiva de forma que se equilibre su acción con el resto de las empresas; (iii) Revisar la fiscalidad de las Entidades de la ES como puede ser el caso de las Cooperativas, rompiendo la clásica idea de que actúan con beneficios fiscales añadidos; (iv) Eliminar las limitaciones para poder operar en cualquier actividad económica, de forma que en todos los ámbitos de actuación empresarial desaparezcan las trabas a las entidades de la Economía Social. Nótese que algunas de estas recomendaciones ya habían sido asumidas uno meses antes a través de la LES y otras coinciden con algunas de los mandatos contenidos en las disposiciones adicionales de dicha norma.

En otro grupo, se sitúan las sugerencias dirigidas a favorecer el reconocimiento estadístico de la ES. Así, el Informe destaca la importancia de crear un registro estadístico de empresas de Economía Social, bajo la supervisión del INE, siguiendo las pautas y criterios metodológicos establecidos por el «Manual Europeo de Cuentas Satélite de las Empresas de la Economía Social» de la Comisión Europea ${ }^{(12)}$. Para eso hay que hacer previamente un catálogo exhaustivo de las diferentes clases de empresas y entidades que integran la Economía Social a partir de esos criterios metodológicos.

También hay una serie de recomendaciones encaminadas al reconocimiento de la ES como interlocutor social; en esta línea destacan las siguientes: (i) Promover la participación directa de las organizaciones de la economía social en los organismos creados por las distintas Administraciones Públicas en los que ya están los restantes agentes socioeconómicos, (ii) Desarrollar una estrategia mediática para profundizar la integración de la Economía Social en el tejido cultural del país, (iii) Avanzar con el proceso de diálogo social en materia de la Economía Social, que se ha estimulado con la Subcomisión. En este sentido, se recomienda profundizar en el proceso de diálogo en un doble plano, desde las administraciones autonómicas y a través de una mayor colaboración de las organizaciones de la Economía Social con otras organizaciones sociales, como las universidades, los consumidores e inversores, los medios de comunicación y los sindicatos.

Finalmente, las recomendaciones orientadas a reconocer la economía social como agente clave para el logro de determinados objetivos. Así por ejemplo se encuentra las que abogan por: (i) La promoción de un empleo de calidad mediante la estimulación de un programa nacional de capacitación para los actores actuales y aspirantes de la Economía Social, tanto de forma técnica como de forma conceptual, que se dirija desde las organizaciones regionales y locales de cada familia de empresas que integran la economía social, (ii) Integrar las empresas de la Economía Social de manera explícita en la estrategia nacional para la mejora de la productividad, probablemente uno de los principales problemas de la economía española, (iii) Potenciar el papel de las cooperativas agrarias como motor de desarrollo rural, (iv) Fomentar las sociedades laborales como forma de cumplir con el mandato constitucional de que los poderes públicos establecerán las medidas que faciliten el acceso de los trabajadores a la propiedad de los medios de producción; (v) Fomentar las Mutualidades de Previsión Social, como uno de los instrumentos más idóneos para canalizar las pensiones de jubilación e incapacidad, así como la asistencia sanitaria de los ciudadanos, que complemente a la Seguridad Social Públicas; (vi) La creación de políticas públicas de fomento de empresas de la Economía Social que puedan apoyar y desarrollar esta forma de hacer empresa entendiendo que, como indicaba el Informe Toia, dichas políticas deben considerarse una auténtica inversión en la creación de redes de solidaridad que puedan fortalecer el papel de las comunidades y autoridades locales en el desarrollo de las políticas sociales.

En el año 2015, cuatro años después de la publicación de la LES y del Informe sobre la Economía social y casi siete años después

salida de la crisis $(2012 / 2321(\mathrm{INI}))$ insistía en la necesidad de reconocer la contribución de las cooperativas en la salida de la crisis señalando que "muchas cooperativas han demostrado ser incluso más resistentes que muchas empresas convencionales en tiempos de crisis, tanto si atendemos a los índices de empleo como a los cierres de actividades" y añadía que "pese a la crisis, se han creado cooperativas en sectores nuevos e innovadores y que existen pruebas convincentes de su solidez, especialmente en lo que respecta a las cooperativas bancarias y a las cooperativas industriales y de servicios (cooperativas de trabajo, sociales y constituidas por PYME". Tras constatar la resiliencia de la fórmula cooperativa en periodos de recesión, el Informe se detiene sobre una serie de aspectos en los que se requiere una acción decidida de la UE y de los Estados miembros para reforzar la "capacidad intrínseca de resistencia" de estas entidades.

(12) El documento está disponible en el siguiente enlace: http://www.ciriec.ulg.ac.be/wp-content/uploads/2015/12/Manual-Satellite AccountsESP 2006.pdf 
de que estallara la crisis financiera, coincidieron dos iniciativas relacionadas con la ES. La primera de ellas es el "Programa de Fomento e Impulso de la Economía Social 2015-2016" de 25 de julio, un proyecto con el que el Gobierno de España pretende dar cumplimiento a lo estipulado en la Disposición adicional séptima de la LES respecto a la necesidad de diseñar un programa de impulso de las entidades de la ES. El programa, identifica siete ejes de actuación que engloban un total de 32 medidas "cuyo objetivo es establecer el marco necesario para que la economía social siga fortaleciéndose y continúe siendo un referente de crecimiento económico y creación de empleo estable y de calidad en España".

Los ejes de actuación son los relativos a: (i) El impulso a la creación y fortalecimiento de las empresas y entidades de la ES; (ii) La revisión y actualización del marco jurídico con el objeto de eliminar las limitaciones a las entidades de la ES simplificar trámites y armonizar regímenes; (iii) El apoyo a la internacionalización e innovación de las entidades de la ES; (iv) El desarrollo de la ES en el marco de la agenda europea y mediterránea; (v) El Fomento y fortalecimiento de la participación institucional en el marco de la ES; (vi) La Promoción y difusión de la ES y (vii) El Buen Gobierno y responsabilidad social en el marco de las entidades de la ES. Respecto al Eje 4, referido al desarrollo de la ES en el marco de la agenda europea, el Programa destaca uno de los instrumentos que el Estado Español ha diseñado para contribuir al logro de los objetivos de crecimiento integrador de la Estrategia Europa 2020, el Programa Operativo de Inclusión Social y Economía Social del Fondo Social Europeo 2014-2020 (en adelante, "POISES"). En este sentido, el POISES establece que "La promoción de un crecimiento integrador pasa, entre otros elementos, por reforzar la lucha contra la pobreza, la exclusión social y la discriminación, por garantizar la igualdad de oportunidades en el acceso al mercado laboral y por aprovechar el potencial de la economía social para la recuperación económica", situando, de este modo, la promoción de la economía social como uno de los ejes fundamentales del programa operativo(13).

La segunda iniciativa es una reforma de la LES, la primera y única desde su publicación, operada a través de la Ley 31/2015, de 9 de septiembre, por la que se modifica y actualiza la normativa en materia de autoempleo y se adoptan medidas de fomento y promoción del trabajo autónomo y de la Economía Social. Esta norma se dicta en cumplimiento del mandato del Real DecretoLey $8 / 2014$, de 4 de julio de medidas urgentes anticrisis y a favor del autoempleo, ratificado posteriormente por el artículo 121 de la Ley $18 / 2014$, de 15 de octubre de aprobación de nuevas medidas urgentes para el crecimiento, la competitividad y la eficiencia.

La Ley de 2015 introduce las modificaciones a través de su artículo tercero incorporando a la LES una serie de preceptos que recogen distintos tipos de incentivos para las entidades de la ES. En primer lugar, el (nuevo) artículo 9 LES describe incentivos a la incorporación de trabajadores a entidades de la economía social|(14) consistentes, por un lado, en bonificaciones en las cuotas empresariales de la Seguridad Social durante tres años aplicables a las cooperativas y sociedades laborales que incorporen trabajadores desempleados como socios trabajadores o de trabajo, y que sean menores de treinta años, o menores de treinta y cinco años que tengan reconocido un grado de discapacidad igual o superior al 33 por ciento. En el caso de sociedades cooperativas, estas bonificaciones se aplican cuando estas entidades hayan optado por un Régimen de Seguridad Social propio de trabajadores por cuenta ajena.

Por otro lado, bonificaciones en las cuotas de la Seguridad Social aplicables a las empresas de inserción en los supuestos de contratos de trabajo suscritos con personas en situación de exclusión social incluidas en el artículo 2 de su normativa específica. El (nuevo) artículo 10 LES recoge la capitalización de la prestación por desempleo a los beneficiarios de prestaciones cuando pretendan incorporarse como socios trabajadores o de trabajo en cooperativas o en sociedades laborales estableciendo una serie de reglas que en ningún caso deben conculcarse para permitir dicha capitalización. El (nuevo) artículo 11 LES enumera una serie de bonificaciones de cuotas de la Seguridad Social de los socios trabajadores o socios de trabajo de las sociedades cooperativas, sustituidos durante los períodos de descanso por maternidad, adopción, acogimiento, paternidad, riesgo durante el embarazo o riesgo durante la lactancia natural, mediante los contratos de interinidad bonificados, celebrados con desempleados a que se refiere el Real Decreto-Ley 11/1998, de 4 de septiembre. Finalmente, el (nuevo) artículo 12 LES prevé, con determinadas condiciones, que quienes sean titulares del derecho a la prestación por cese de actividad, y tengan pendiente de percibir un período de, al menos, seis meses, puedan percibir de una sola vez el valor actual del importe de la prestación, cuando acrediten ante el órgano gestor que van a realizar una actividad profesional como

(13) En fechas recientes, tuvimos conocimiento de la Resolución de 15 de marzo de 2018, de la Secretaría de Estado de Empleo, por la que se publica el Acuerdo del Consejo de Ministros de 29 de diciembre de 2017, por el que se aprueba la Estrategia Española de Economía Social 2017-2020.

(14) Artículo 9 LES. 
El ejercicio de la actividad aseguradora por las empresas de la Economía Social: una revisión crítica de la situación en España

socios trabajadores de una cooperativa de trabajo asociado o sociedad que tenga el carácter de laboral.

A la vista de lo expuesto, estamos en condiciones de efectuar algunas valoraciones respecto al desarrollo de la ES en nuestro país. Aun concediéndole el mérito de haber sido pionero en el reconocimiento jurídico de este sector mediante la elaboración de LES, no son pocos los que advierten sobre la escasa o nula efectividad de esta norma desde su entrada en vigor. Siguiendo en este punto las reflexiones de Pérez Uralde $(2017,134-158)$ conviene recordar en primer lugar que la LES no ha tenido desarrollo reglamentario pese a la expresa habilitación al Gobierno contenida en la Disposición final segunda. Particularmente flagrante es la ausencia de un reglamento que contemple el funcionamiento y composición del Consejo para el Fomento de la Economía Social, un órgano que, de hecho, ni siquiera ha desarrollado funciones especialmente relevantes encomendadas por la propia LES como la consistente en "informar y colaborar en la elaboración de proyectos sobre cualquier disposición legal o reglamentaria que afecten a entidades de la economía social". Prueba de ello es que la reforma operada por la Ley 31/2015, de 9 de septiembre no fue objeto de consulta por el citado Consejo. Precisamente otra de las criticas van dirigidas a dicha reforma en el sentido que las medidas introducidas en la LES son cuestiones que deberían haber sido reguladas mediante simples decretos al ser medidas coyunturales, muy concretas o propias de una norma distinta a la LES $(2017,144)$.

Sin embargo, el principal reproche se dirige a la propia falta de aplicación de la LES y, más en particular, a las medidas contempladas en la Disposición adicional séptima. Recuérdese que esta Disposición instaba al Gobierno a aprobar en el plazo de seis meses desde la entrada en vigor, un programa de impulso de las entidades de la ES que reflejara una serie de medidas como la actualización de la norma reguladora de las Sociedades Laborales, la Ley de Subvenciones y, con carácter general, revisar la normativa necesaria para eliminar las limitaciones de las entidades de la economía social, de forma que estas puedan operar en cualquier actividad económica sin trabas injustificadas; pues bien, el balance no es demasiado prometedor: el Programa de Fomento e Impulso de la Economía Social tardó cuatro años en ser aprobado y, hasta la fecha, no se ha producido la revisión de la Ley de Subvenciones aunque si la actualización y revisión de la Ley 4/1997, de 24 de marzo, de Sociedades Laborales, mediante la aprobación de la Ley 44/2015, de 14 de octubre de Sociedades Laborales y Participadas.
En cuanto a la revisión de "la normativa necesaria para eliminar las limitaciones de las entidades de la economía social", pese a que esta era una petición que no sólo se recogía en la LES, sino también en el Informe sobre la Economía Social de 2011 y en Eje 2 del Programa de Fomento e Impulso de la Economía Social 2015-2016, no se ha realizado ningún esfuerzo solvente y sistemático para llevarla a cabo. Pero lo cierto es que la citada revisión es la piedra angular sobre la que debería proyectarse el desarrollo efectivo de la ES ya que el ordenamiento jurídico español presenta importantes deficiencias en la articulación de las singularidades de las empresas de la ES que pueden comprometer su viabilidad a corto y medio plazo. En el siguiente epígrafe daremos cuenta de un ejemplo paradigmático de esta situación que permitirá concluir hasta qué punto es necesario la citada revisión normativa para permitir que las empresas de la ES puedan desplegar todo su potencial.

\section{El reconocimiento de los rasgos singulares de las entidades de la Economía Social en el mercado de seguros: un reto pendiente del legislador español que permita desplegar todo su potencial y asegurar el pluralismo empresarial en el sector}

Los datos del informe de la Dirección General de Seguros y Fondos de Pensiones correspondiente a $2017^{(15)}$, señala que el número de entidades de operativas inscritas en el Registro administrativo de entidades aseguradoras en España a 31 de diciembre de 2017 era de $224^{(16)}$ de las cuales 145 eran sociedades anónimas y el resto entidades de la economía social: 31 mutuas de seguros y 49 mutualidades de Previsión Social de ámbito

(15) El Informe se elabora anualmente por la Dirección General de Seguros y Fondos de Pensiones, un órgano administrativo que depende de la Secretaría de Estado de Economía y Apoyo a la Empresa, adscrita al Ministerio de Economía y Empresa. Dicho Informe incluye los principales datos del mercado asegurador y de los fondos de pensiones obtenidos a partir de la información suministrada principalmente por las entidades supervisadas. Junto a ello, realiza un estudio pormenorizado de las diferentes funciones desarrolladas por la Dirección General de Seguros y Fondos de Pensiones. Por último, incluye un análisis del marco regulatorio nacional así como del entorno internacional en el que se desenvuelve el mercado asegurador

(16) Esta cifra se ha ido reduciendo progresivamente en los últimos años debido principalmente a procesos de reestructuración societaria y de reordenación bancaria. Este último factor ha llevado a la desaparición de un importante número de entidades financieras, básicamente cajas de ahorro, lo que forzó la renegociación de los acuerdos de banca seguros existentes hasta la fecha. 
estatal ${ }^{(17)}$. Sin entrar en consideraciones sobre la inveterada atomización del sector, lo cierto es que la presencia de entidades de la ES en el mercado de seguro español es minoritaria en términos cuantitativos y, además, hay que recordar que no se ha constituido ninguna cooperativa de seguros. Las razones de este exiguo balance son diversas pero, sin duda, están relacionadas con la falta de comprensión de la naturaleza empresarial o del modelo societario de las entidades que integran la ES. Falta de comprensión que se traduce en propuestas normativas que toman como referencia primordial la forma jurídica dominante, por ejemplo: sociedades de capital, ignorando al resto o, lo que es peor, favoreciendo procesos de isomorfismo organizativo(18) que conducen al desvirtuamiento de los atributos esenciales de las empresas de la ES y a su convergencia con el tipo societario preponderante $^{(19)}$.

Los fenómenos descritos son flagrantes en las leyes de ordenación y supervisión del seguro privado españolas que han ido sucediéndose desde 1908 y no sólo por el tardío reconocimiento de las cooperativas de seguros, sino también por el tratamiento fragmentario dispensado a los aspectos societarios de las aseguradoras de la ES que se manifiesta en la existencia de auténticos vacíos normativos con aplicación analógica del régimen jurídico de la sociedad anónima y consecuente desatención a los rasgos que configuran la naturaleza específica del tipo societario. Ello resulta especialmente grave en las sociedades mutuas habida cuenta que la norma sectorial constituye su única fuente de derecho disponible. Esta situación se mantiene sin cambios significativos en la vigente Ley 20/2015, de 14 de julio, de ordenación, supervisión y solvencia de las entidades aseguradoras y reaseguradoras (en adelante, "LOSSEAR") con la que se impulsa una profunda reforma de la normativa de rango legal y reglamentario sobre ordenación y supervisión de los seguros privados como consecuencia de la transposición de la Directiva 2009/138/CE, del Parlamento Europeo y del Consejo, de 25 de noviembre de 2009, sobre el seguro de vida, el acceso a la actividad de seguro y de reaseguro y su ejercicio (Solvencia II) ${ }^{(20)}$. Seguidamente analizaremos con detalle algunos de los aspectos mencionados.

\subsection{El tardío y vacilante reconocimiento de la aptitud de las cooperativas de seguros para el ejercicio de la actividad aseguradora} La actividad aseguradora exige una organización del empresario que ofrezca suficientes garantías de solidez y solvencia para hacer frente a su función básica consistente en la compensación de riesgos ${ }^{(21)}$. Por este motivo la legislación de los diferentes países y también la española sólo autorizan un reducido número de formas jurídicas para ejercer dicha actividad. En particular, el artículo 27.1 LOSSEAR hace referencia a la sociedad anónima, como fórmula societaria paradigmática de las sociedades de capital y tres formas institucionales típicas del subsector de mercado o empresarial de la Economía Social: cooperativas, mutuas y mutualidades de previsión social ${ }^{(22)}$.

Sin embargo, conviene recordar que el reconocimiento legal de la aptitud de las sociedades cooperativas para el ejercicio de la actividad aseguradora no se produce hasta la Ley 33/1984, de 2 de agosto, sobre Ordenación del Seguro Privado ${ }^{(23)}$ precisamente porque uno de sus objetivos era "normalizar el mercado, dando a todas las entidades aseguradoras la posibilidad de participar en el mismo régimen de absoluta concurrencia y sin tratamientos legales discriminatorios"(24). De hecho, la norma citada permitía que las sociedades cooperativas

(17) Se trata de mutualidades sometidas al control de la Dirección General de Seguros y Fondos de Pensiones. Por otro lado existen 232 mutualidades de previsión social de ámbito autonómico destacando la Comunidad Autónoma del País Vasco con 169 y la Comunidad Autónoma de Catalunya con 34.

(18) El isomorfismo constituye uno de los conceptos esenciales de la teoría institucional. P. J. DiMaggio y W. Powell lo definen del siguiente modo: "[I]somorphism is a constraining process that forces one unit in a population to resemble other units that face the same set of environmental conditions". En particular, el isomorfismo institucional constituye un proceso de homogenización entre las organizaciones sujetas a presiones similares por efecto del ambiente institucional. Véase de los autores, "The iron cage revisited institutional isomorphism and collective rationality in organizational fields", American Sociological Review 48, (1983): 147-160.

(19) Esta circunstancia ha sido señalada por los expertos como uno de los riesgos más importantes de las empresas de la economía social Sobre esta cuestión véanse los sucesivos Informes sobre La Economía Social en la Unión Europea elaborados para el Comité Económico y Social Europeo por los profesores José Luis Monzón y Rafael Chaves del Centro Internacional de Investigación e Información sobre la Economía Pública, Social y Cooperativa (CIRIEC). El más reciente está disponible en: https://publications.europa.eu/es/publicationdetail/-/publication/c1f1e8e6-bd27-11e7-a7f8-01aa75ed71a1

(20) DOUE 2009/ L 335/1.

(21) Apartado 2.59 del Reglamento (UE) núm. 549/2013 del Parlamento Europeo y del Consejo de 21 de mayo de 2013 relativo al Sistema Europeo de Cuentas Nacionales y Regionales de la Unión Europea (DOUEL núm. 174 de 26 de Junio de 2013).

(22) Junto a ellas, el precepto admite también: la sociedad anónima europea y la sociedad cooperativa europea.

(23) Artículo 7 de la Ley 33/1984, de 2 de agosto, sobre Ordenación del Seguro Privado A propósito de este precepto véanse los comentarios de Justino F. Duque, "Mutuas y Cooperativas en la nueva legislación", Comentarios a la Ley de Ordenación del Seguro Privado, (Madrid, 1988), 311-388.

(24) De la Exposición de Motivos de la LOSP. Para un detallado estudio de la evolución en el reconocimiento jurídico del cooperativismo de seguros véase María José Puyalto, La cooperativización de los seguros agrarios, (Barcelona, 1999), 113 y siguientes. 


\section{El ejercicio de la actividad aseguradora por las empresas de la Economía Social: una revisión crítica de la situación en España}

de seguros pudieran ejercer la actividad aseguradora para cubrir riesgos a sus socios y como forma de trabajo asociado para cubrir riesgos a cualquier asegurado ${ }^{(25)}$. Esta doble posibilidad era una consecuencia natural de las modalidades que las cooperativas de primer grado pueden adoptar en función del tipo de participación de los socios en el proceso de producción y distribución, distinguiendo así entre sociedades cooperativas en que los socios participan en los flujos reales como proveedores (cooperativas de trabajo asociado) y aquellas otras en las que la participación es como consumidores (cooperativas de consumo). De forma inopinada ${ }^{(26)}$, la existencia de cooperativas de seguros de trabajo asociado quedó vedada por la Ley 30/1995 de 8 de noviembre de Ordenación y Supervisión de los Seguros Privados que también derogó la referencia a este tipo de cooperativas en la Ley 3/1987, de 2 de abril, General de Cooperativas. Esta situación se ha mantenido sin cambios en la vigente LOSSEAR.

Lo cierto es que las limitaciones de la formula cooperativa en el ámbito del seguro privado ya había sido recogida en el "Informe sobre la Economía Social" aprobado por la Comisión de Economía y Hacienda del Congreso de los Diputados en 2011. En efecto, al hilo de una de las recomendaciones del Informe en que abogaba por eliminar las trabas a las entidades de la ES para operar en cualquier actividad económica, incidía en el hecho que las cooperativas:

"tropiezan con obstáculos legales para ejercer su actividad en algunos ámbitos especialmente regulados (...) situación que provoca dificultades para su desarrollo y en muchos casos obliga a la constitución de sociedades mercantiles de capital, sociedades anónimas o limitadas, de carácter instrumental, esto es, de capital bajo el control de las cooperativas, situación muy perjudicial para las cooperativas. También se constata que las principales actividades en las que no se autoriza la intervención de las cooperativas son: la distribución y comercialización de la electricidad, gasolina y gas, las farmacias, agencias de viaje y los seguros".

En éste último caso (los seguros), el Informe hacía referencia, precisamente, a la prohibición del ejercicio de la actividad aseguradora por cooperativas de trabajo asociado, por lo que entendemos que la sugerencia va en la línea de "readmitir" esta modalidad en el ejercicio de la actividad aseguradora. Cierto es que los asegurados no serían al mismo tiempo socios de la entidad aseguradora pero podrían beneficiarse, siquiera reflejamente, por una eventual buena organización de la empresa aseguradora derivada de la coincidencia entre la cualidad de empresario y trabajador ${ }^{(27)}$.

Por otra parte, es probable que una de las causas por las que no exista en nuestro país ninguna experiencia de aseguramiento cooperativo, radique en la dificultad de impulsar una iniciativa de este tipo desde y por los consumidores de seguros, en cambio, el interés demostrado por algunos colectivos profesionales (especialmente médicos) por constituir cooperativas de seguros de trabajo asociado en lugar de tener que recurrir a una sociedad anónima propiedad mayoritaria de cooperativas sanitarias de trabajo asociado(28) puede ser un elemento a tener en cuenta por el legislador español para el fomento de este tipo de entidades.

Sin perjuicio de lo anterior, la ausencia de cooperativas de seguros también puede explicarse por la presencia de lo que algunos autores denominan tipos fronterizos como es el caso de las sociedades mutuas ${ }^{(29)}$. En realidad, un sector de la doctrina opina que las mutuas pueden considerarse sociedades cooperativas específicas del ámbito operativo de la actividad aseguradora ${ }^{(30)}$. Incluso las propias normas jurídicas han incurrido en esta asimilación. El Real Decreto 2710/1978 de 16 de noviembre por el que se aprobaba el reglamento de la Ley 52/1974, de 19 de diciembre, General de Cooperativas (coetánea, por cierto, de la Ley de Ordenación de 1954) mantenía la tesis que el cooperativismo de seguros se realizaba (o debía realizarse) por las mutuas. Así su artículo 122 señalaba que: "las cooperativas de seguros podrán crear mutualidades de seguros

(25) Artículo 15 de la Ley 33/1984, de 2 de agosto, sobre Ordenación del Seguro Privado.

(26) Algunos autores aventuran que esta omisión se debe, entre otros motivos, al hecho que durante la vigencia de la ley de 1984 no llegó a constituirse ninguna cooperativa de ésta clase. En este sentido, Carmen Núñez Lozano, Ordenación y Supervisión de los Seguros Privados, (Marcial Pons, 1998), 85.

(27) Tomamos el argumento de Justino F. Duque, 314.

(28) Como ejemplo de lo que estamos diciendo es la Cooperativa Sanitaria de ámbito estatal Lavinia, creada hace 40 años que agrupa a más de 10.000 médicos. Lavinia es la propietaria de la aseguradora Asistencia Sanitaria Interprovincial S.A. (ASISA).

(29) Narciso Paz Canalejo, "Las cooperativas de seguros", Revista Española de Seguros 29 (1982): 90.

(30) Carlos García-Gutiérrez Fernández, "Las sociedades cooperativas de derecho y las de hecho con arreglo a los valores y a los principios del Congreso de la Alianza Cooperativa Internacional de Manchester en 1996: Especial referencia a las sociedades de responsabilidad limitada reguladas en España”, REVESCO 61 (1995): 69 nota (68). También José Fernando Merino Merchán, "Consideraciones generales sobre el cooperativismo de seguros en España", Revista de Derecho Mercantil 151 (1979): 109 y ss. A propósito de la Ley de Ordenación de 16 de diciembre de 1954 que omitía cualquier referencia a la cooperativa como fórmula societaria del empresario de seguros, este último autor señalaba que no había dificultades para la creación de una cooperativa de seguros en la medida que ésta constituye un modelo paradigmático de la asociación mutua. Tal circunstancia legitimaría, siempre en opinión del autor, la inclusión de la Cooperativa de seguros en el concepto de mutua. 
en las que únicamente podrán ser mutualistas los socios de las cooperativas creadoras". A mayor abundamiento, en la primera norma sectorial que reconoce expresamente el cooperativismo asegurador (LOSP) el criterio definidor no era la distinción entre mutuas y cooperativas sino la distinción entre entidades que practicaban el seguro a prima fija y las que operaban a prima variable ${ }^{(31)}$.

A nuestro juicio, el argumento definitivo que explica la inveterada confusión entre Mutuas y Cooperativas se encuentra en la finalidad mutualista que ambas comparten en el ámbito del seguro. En efecto, la mutualidad entendida como un conjunto de personas que soportan riesgos homogéneos y contribuyen recíprocamente a reparar las consecuencias de los siniestros que afecten a una de ellas, constituye uno de los principios fundamentales que sustentan la institución aseguradora. En la explotación del seguro realizada por sociedades anónimas, esta mutualidad es puramente económica, es decir, los asegurados disfrutan también del carácter de mutualistas pero este rasgo carece de relevancia porque pasa a primer plano la figura del intermediario (la sociedad anónima). De este modo junto, al interés de los asegurados de cubrirse contra el riesgo coexiste el interés de los accionistas de obtener lucro de la explotación industrial del seguro (Garrigues 1982, 627). Por el contrario, cuando el titular de la empresa aseguradora es uno de los tipos societarios de la ES (Cooperativas o Mutualidades) existe identidad entre la comunidad de sujetos expuesta al riesgo y la comunidad personal societaria, lo que nos lleva a afirmar que en estas sociedades los asegurados gestionan directamente los intereses colectivos constituyéndose en portadores del riesgo empresarial. Sin embargo, debemos tener en cuenta que, salvo el supuesto de cooperativas de crédito y de seguros, el principio de mutualidad no está presente en el resto de cooperativas puesto que en las de consumo no se compran ni se venden bienes recíprocamente sino que los adquieren o los enajenan en común y en cuanto a las de trabajo asociado no trabajan unos para otros sino conjuntamente (Monzón 1995, 51). Dicho de otro modo, la mutualidad no es un principio inherente a la cooperativa en cuanto tipo social como, contrario sensu, ocurre con la sociedad mutua.

\subsection{El cuestionable tratamiento dicotómico de la mutua y de la mutualidad en la LOSSEAR}

La confusión entre la sociedad cooperativa de seguros y la mutua contrasta vivamente con el tratamiento dicotómico que el legislador dispensa a las mutuas y a las mutualidades de Previsión Social. Tradicionalmente se ha mantenido que la especialización operativa de las mutualidades, consistente en el ejercicio de una modalidad aseguradora de carácter voluntario complementaria al sistema de Seguridad Social obligatoria, mediante aportaciones de los mutualistas, personas físicas o jurídicas, o de otras entidades o personas protectoras ${ }^{(32)}$, constituye un elemento distintivo respecto a las mutuas hasta el punto de considerarlas como un tipo societario autónomo. Este planteamiento se traduce en un estatuto jurídico diferenciado que para las mutuas se encuentra en la norma de control y para las mutualidades de previsión social de ámbito estatal fundamentalmente en el Real Decreto 1430/2002, de 27 de diciembre, por el que se aprueba el Reglamento de mutualidades de previsión social (en adelante, RMPS). Adicionalmente, las Comunidades Autónomas ostentan competencia exclusiva en la materia siempre que las mutualidades de previsión social tengan su domicilio social, ámbito de operación y asunción de compromisos (en el caso de seguros de vida), o localización de riesgos (respecto de seguros distintos del de vida), dentro del ámbito espacial de la Comunidad Autónoma. Concretamente tienen competencia en lo relativo a su organización y funcionamiento, y les corresponde conceder la autorización administrativa y su revocación, previo informe de la Administración General del Estado.

En nuestra opinión, las mutuas y mutualidades de previsión constituyen un único tipo societario a pesar de sus diferencias operativas. Las razones que avalan esta conclusión son diversas. En efecto, aunque las formas institucionales que integran la ES pueden variar significativamente de un país a otro, existe un núcleo común integrado por cooperativas y mutualidades, como formas genuinas nacionales que los expertos han considerado ser integrantes de la ES de su país. De hecho, la propia LES avala este paradigma cuando, al enunciar las entidades que integran la $\mathrm{ES}$, se refiere a las cooperativas y mutualidades, utilizando éste último término como comprensivo de las mutuas y las mutualidades de previsión social. Más aún, la diferencia entre entidades que ejercen la previsión social y el seguro mutuo no existe en otros países europeos, donde solo hay una clase de mutualidad, llamada también sociedad mutua de seguros o sociedad de seguros mutuos. Este es el caso de Francia que las contempla en el Code de la Mutualité o Bélgica en la Loi du 6 aout 1990, relative aux mutualites et aux unions nacionales des

(31) Artículo 13.1 y 41 de la LOSP.

(32) Artículo 43.1 LOSSEAR, junto a ellas se encuentran mutualidades de previsión social que se encuentran reconocidas como alternativas a la Seguridad Social en la disposición adicional decimoquinta de la Ley 30/1995, de 8 de noviembre, de Ordenación y Supervisión de los Seguros Privados, ejercen además una modalidad aseguradora alternativa al alta en el Régimen Especial de la Seguridad Social de los Trabajadores por Cuenta Propia o Autónomos. 
mutualites. Por otra parte, entre los instrumentos opcionales europeos de carácter societario se encuentra una propuesta de reglamento sobre estatuto de la mutualidad europea ${ }^{(33)}$ que se uniría a los ya existentes sobre la sociedad cooperativa (Reglamento (CE) 1435/2003 de 22 de julio de 2003, del Consejo relativo al estatuto de la sociedad cooperativa europea) y la sociedad anónima europea (Reglamento del Consejo (CE) 2157/2001, de 8 de octubre de 2001, por el que se aprueba el estatuto de la Sociedad Anónima Europea).

Finalmente, a pesar que las mutualidades están sometidas a estatutos jurídicos muy diversos en la Unión Europea el "Manual de la Comisión Europea para la elaboración de las cuentas satélite de las empresas de la economía social" se anima a ofrecer una definición, común a todas ellas, que las describe como una asociación autónoma compuesta por personas físicas o morales que se han agrupado de forma voluntaria con la perspectiva, esencialmente, de satisfacer necesidades comunes en los sectores del seguro (vida y no vida), de la previsión de la salud y de los bancos, y cuyas actividades están sometidas a la competencia. Se administra en virtud de un principio de solidaridad entre los miembros que participan en el gobierno de la empresa y obedece a los principios de ausencia de acciones, libertad de adhesión, fines no exclusivamente lucrativos, solidaridad, democracia y autonomía de gestión.

Si aceptamos que la mutua y la mutualidad de previsión constituyen un único tipo societario llámese sociedad mutua o mutualidad (éste último parece ser el término más utilizado en el ámbito europeo) la consecuencia más evidente sería la articulación de un régimen jurídico común que contemplará la regulación de los aspectos estrictamente societarios en una norma distinta de la de control. Sobre este particular, entraremos en detalle en el siguiente epígrafe.

\subsection{La problemática regulación de los aspectos societarios de la mutua en la LOSSEAR}

De los tipos societarios disponibles en el ordenamiento jurídico español para el ejercicio de la actividad aseguradora, las mutuas son las grandes olvidadas. De hecho, hasta no hace mucho se mantenían encendidos debates doctrinales acerca de su mercantilidad ${ }^{(34)}$. Asimismo hay que alertar sobre una circunstancia sin parangón en el panorama societario, esta es, la ausencia de una norma legal que regule sus aspectos estrictamente societarios. En efecto, la única fuente disponible para las mutuas se encuentra en las propias normas de control sectoriales. La ubicación del régimen jurídico de una persona jurídica privada (sociedad) en una norma pública reguladora de una actividad financiera, causa una mezcolanza de aspectos societarios, técnicos y contractuales, relativos estos últimos al contrato de seguro, que no siempre se resuelven a favor del mutualista.

Por tanto, una de las propuestas de lege ferenda que deberían ser atendidas por el legislador español es dotar de una regulación propia a las mutuas en una norma independiente de la de supervisión que, como mínimo, tuviera el mismo rango que las que regulan el resto de tipos societarios. Somos conscientes que frente a esta propuesta puede alegarse que las mutuas se regulan en la norma de supervisión porque se dedican exclusivamente a la actividad aseguradora; sin embargo, este argumento puede neutralizarse fácilmente cuando se comprueba que existe un tipo de entidad de crédito, concretamente la Sociedad de Garantía Recíproca, que sólo puede tener como objeto social "el otorgamiento de garantías personales, por aval o por cualquier otro medio admitido en derecho distinto del seguro de caución, a favor de sus socios para las operaciones que éstos realicen dentro del giro o tráfico de las empresas de que

(33) En 1992, la Comisión presentó tres propuestas de reglamento con objeto de adoptar, respectivamente, el estatuto de la sociedad cooperativa europea (SCE), el de la asociación europea (AE) y el de la mutualidad europea (ME). Cada uno de los reglamentos se complementaba con una directiva relativa al cometido de los trabajadores. Con esos textos se pretendía dotar a esos tres modelos de sociedades (cooperativa, asociación y mutualidad) de un instrumento jurídico que les permitiera desarrollar sus actividades transnacionales en toda la Unión Europea, ya que el estatuto de la sociedad europea (SE), que entonces se debatía, no aportaba soluciones adecuadas a sus especificidades. Las tres propuestas fueron modificadas en 1993 para tener en cuenta los dictámenes del Comité Económico y Social Europeo y del Parlamento Europeo14. El grupo «Derecho de sociedades» del Consejo trabajó sobre estos textos hasta 1996, año en que surgieron diferencias insalvables entre los Estados miembros en torno al estatuto de la SE (y, más concretamente, sobre la directiva relativa al cometido de los trabajadores) que paralizaron los trabajos sobre todos los estatutos. En la cumbre de Niza de diciembre de 2000 se alcanzó un compromiso. estatutos, comenzando por el de la SCE. A continuación debía acometerse el de la AE y, finalmente, el de la ME. El estatuto de la SCE fue adoptado en julio de 2003, y los trabajos sobre la AE avanzaron mucho durante la Presidencia griega (primer semestre de 2003). Tal como se señala en la Comunicación de la Comisión sobre la modernización del Derecho de sociedades 16: «la Comisión tiene intención de apoyar activamente el proceso legislativo iniciado a este respecto [sociedad cooperativa europea y otras formas jurídicas de empresas en la UE], como respuesta al deseo, explícitamente expresado por el Parlamento Europeo, de prestar una atención significativa al desarrollo de nuevas formas jurídicas de empresas europeas.

(34) Entre otros, Alberto Bercovitz y Manuel Broseta, "Consideraciones sobre la naturaleza jurídica de las mutuas de seguros", Revista Española de Seguros, № 46, 1986, 133 y ss; José Antonio Carro del Castillo, "Naturaleza jurídica de las mutuas de seguros", Comentarios a la Ley de Ordenación del Seguro Privado, Madrid, 1986, 423 y siguientes; Juan José Garrido Comas, Ensayo para una teoría de la mutualidad, Barcelona 1960. 
sean titulares" y, sin embargo, dispone de una norma propia que contempla su régimen jurídico ${ }^{(35)}$.

Pero con independencia de lo anterior, en nuestra opinión conviene abrir el foco y contemplar la posibilidad que la mutua no sea una fórmula societaria exclusiva del ámbito del seguro sino la personificación de los consumidores en el ejercicio de una determinada actividad económica. Desde esta perspectiva, la sociedad mutua adquiere sustantividad propia e independiente de la actividad que realiza pero participando de los principios que inspiran al resto de entidades de la economía social. El fenómeno de la mutualización del seguro y la subsiguiente asociación entre el tipo societario y la actividad económica concretamente contemplada se debe, entre otras razones, al principio de mutualidad económica que sustenta la institución aseguradora a la que ya hemos hecho referencia. Por ello no es de extrañar que la fórmula asociativa fuera la primera en aparecer en la historia del seguro incluso para cubrir riesgos tan complejos como los que afectan a la explotación agraria. Consecuentemente con lo expuesto, los aspectos societarios no aparecen como instrumentales sino justo lo contrario. Instrumental es la actividad que se mutualiza, de ahí la necesidad, una vez más, de contar con una norma independiente de la de supervisión de seguros que articule los rasgos característicos de estas entidades y defina con claridad la posición jurídica del socio.

\subsection{Las injustificables remisiones al régimen jurídico de la sociedad anónima: en particular, las referidas el estatuto jurídico del mutualista}

Al problema analizado en el epígrafe anterior sobre la ubicación del régimen jurídico de las mutuas en las normas de control, debe añadirse el carácter fragmentario de dicho régimen que se traduce en la existencia de auténticos vacíos normativos que se resuelven, en última instancia, mediante una remisión al régimen jurídico de la sociedad anónima, en cuanto no contradiga el régimen específico de esta clase de entidades. Esta situación también es predicable, aunque en menor medida, respecto de las mutualidades de previsión social y las cooperativas de seguros. En el caso de estas últimas, basta con decir que el artículo 42 d) LOSSEAR, después de dedicar unas breves normas para este tipo societario, dispone que en lo no previsto, "se regirán por las disposiciones de esta Ley, su desarrollo reglamentario, y por los preceptos del texto refundido de la Ley de Sociedades de Capital a los que se remite, así como por las disposiciones reglamentarias que la desarrollen y, supletoriamente, por la legislación de cooperativas". En definitiva, no sólo se discrimina negativamente el fenómeno mutualista en su conjunto, sino que el perjuicio se traslada al propio mutualista habida cuenta que la falta de una adecuada articulación de las relaciones internas de la sociedad provoca la indefinición de su posición jurídica no sólo respecto al resto de los socios sino también, respecto a la propia sociedad.

La vigente LOSSEAR únicamente dedica a los aspectos societarios de las mutuas un precepto con tres apartados. El primer apartado del artículo 41 está dedicado a definirlas como "sociedades mercantiles sin ánimo de lucro, que tienen por objeto la cobertura a los socios, sean personas físicas o jurídicas, de los riesgos asegurados mediante una prima fija pagadera al comienzo del período del riesgo". El segundo permite la constitución de grupos mutuales conforme a los requisitos que se establezcan reglamentariamente. Finalmente, el tercer apartado dispone que en los casos de disolución de la mutua y en los de transformación, fusión y escisión en que la entidad resultante de la transformación o fusión, o beneficiaria de la escisión sea una sociedad anónima, así como en los de cesión global de activo y pasivo, los mutualistas actuales y los que lo hubiesen sido en los cinco últimos años, o con anterioridad si así lo prevén los estatutos, percibirán, al menos, la mitad del valor del patrimonio de la mutua.

El resto de previsiones societarias relativas a la mutua se contienen en el artículo 9 del Real Decreto Legislativo 6/2004, de 29 de octubre, por el que se aprueba el texto refundido de la Ley de ordenación y supervisión de los seguros privado (en adelante "TRLOSSP") (35) $\mathrm{y}$, fundamentalmente, en su reglamento aprobado por Real Decreto 2486/1998, de 20

(35) La propia exposición de motivos de la Ley 1/1994, de 11 de marzo, sobre Régimen Jurídico de las Sociedades de Garantía Recíproca argumentaba que "El Real Decreto 1885/1978 remitía genéricamente a la Ley de Sociedades Anónimas como derecho subsidiario. Tal solución creaba dificultades a la hora de determinar qué artículos en concreto de la Ley de Sociedades Anónimas podían ser aplicados a las Sociedades de Garantía Recíproca. Por ello se ha optado por establecer un texto completo y desarrollado sobre el régimen jurídico de las Sociedades de Garantía Recíproca, en el que ciertamente se hacen remisiones a la Ley de Sociedades Anónimas, pero se trata de remisiones puntuales, a artículos concretos, evitando la difícil interpretación que significaba la remisión genérica contenida en el Real Decreto 1885/1978". A mayor abundamiento añade que "El nuevo texto legal respeta las características fundamentales de las Sociedades de Garantía Recíproca establecidas por el Real Decreto 1885/1978, que han contribuido al éxito de la institución. Por consiguiente, en ese aspecto fundamental de la delimitación del tipo societario no se contienen modificaciones esenciales. Las Sociedades de Garantía Recíproca siguen siendo un tipo especial de sociedad, que en lo que se refiere al capital social y a la responsabilidad de los socios por las deudas sociales se asemeja totalmente a una sociedad anónima; pero en lo que se refiere a los derechos de los socios predomina el carácter mutualista".

(35) EI TRLOSSP, por cierto, fue derogado, excepto sus artículos 9, 10 y 24 referidos a las mutuas, mutualidades de previsión social y cooperativas de seguros, que siguen vigentes conforme establece la letra g) de la disposición derogatoria de la LOSSEAR. 


\section{El ejercicio de la actividad aseguradora por las empresas de la Economía Social: una revisión crítica de la situación en España}

de noviembre (en adelante "ROSSP")(36). Es decir, que una parte sustancial del régimen jurídico de la mutua, en tanto que sociedad mercantil, se encuentra en un texto reglamentario. Sobre este hecho ya alertaba Tirado Suárez $(2002,4496)$, cuando a propósito de su análisis sobre la relación mutualista-asegurado, señalaba que "esta deslegalización del estatuto jurídico del mutualista en relación con el funcionamiento societario, supone de hecho una clara discriminación negativa del fenómeno mutualista frente a las demás sociedades mercantiles, cuyo régimen jurídico tiene rango de ley en sentido formal" $(2002,4496)$. Con carácter previo al análisis del conjunto de derechos y deberes que configuran el estatuto jurídico del mutualista es conveniente discernir cómo adquiere esta condición. Es sabido que en las sociedades de capital la posición jurídica del socio se configura técnicamente como partes alícuotas del capital social que responden a las notas de acumulabilidad e indivisibilidad.

Por tanto, el socio queda identificado de forma indirecta a través de la titularidad de una o más partes del capital social (acciones o participaciones) que le atribuyen los derechos reconocidos en la ley y en los Estatutos. En la sociedad cooperativa de seguros, el establecimiento del vínculo entre la sociedad y el socio implica, de un lado, la participación económica del mismo en la sociedad y, de otro, su participación en el objeto social. La primera de estas obligaciones se ha recogido por la Alianza Cooperativa Internacional con una fórmula del siguiente tenor literal "los socios contribuyen equitativamente al capital (y al patrimonio" de sus cooperativas $(\ldots))^{(37)}$. El compromiso de constituir un capital social con las aportaciones de todos los socios que adquieren, de este modo, dicha condición se ha positivizado en todas las leyes de cooperativas del estado español ${ }^{(38)}$. En segundo término, aparece la obligación de realizar operaciones y servicios que le proporciona la sociedad cooperativa, en el caso que nos ocupa, la suscripción de una póliza de seguros. En definitiva, el acceso a la condición de socio, previa resolución favorable del Consejo Rector, se verifica típicamente con la celebración de un contrato de seguros, el pago de la prima correspondiente y la suscripción y posterior desembolso de la Aportación Obligatoria Mínima(39).
Las sociedades mutuas comparten con las cooperativas éste último aspecto. El artículo 11.1.a) del ROSSP dispone que "la condición de mutualista se adquiere a través del contrato de seguro", añadiendo, además, que en el momento de la firma de dicho contrato se entreguen los estatutos de la entidad. Esta particularidad comporta la concurrencia de la condición de socio (de la sociedad) y la de usuario de la actividad desarrollada por la empresa reconocida sin ambages por el legislador español. Así, el artículo 9.2.b) TRLOSSP declara que: “(...). La condición de mutualista será inseparable de la de tomador del seguro o de asegurado", precepto que también es de aplicación, mutatis mutandis, a las mutualidades de previsión social y a las cooperativas. Como han señalado algunos autores:

"el ordenamiento español queda así al margen de la tendencia a la separación de ambas figuras que se observa en otros ordenamientos como el alemán, el holandés y el suizo, países en los que las mutualidades y/o las sociedades cooperativas de seguros pueden asegurar a no socios si los estatutos sociales así lo permiten -aunque con el requisito, en el caso holandés, de que la actividad aseguradora realizada con no socios no tenga más importancia que la realizada con socios-, lo que supone la aproximación a las características de la empresa aseguradora capitalista convencional" (Moreno 2002, 441-457) ${ }^{(40)}$.

Un problema clásico en los estudios sobre mutuas hace referencia a la cuestión de quien adquiere la condición de socio/mutualista cuando la cualidad de tomador y asegurado

(36) EL ROSSP también fue derogado excepto por lo relativo a las mutuas, mutualidades de previsión social y cooperativas de seguros por el subapartado ii) de la letra a) de la disposición derogatoria única del ROSSEAR.

(37) La Alianza Cooperativa Internacional conocida por sus siglas ACl en castellano, es una organización no gubernamental independiente fundada en 1895 que reúne, representa y sirve a organizaciones cooperativas en todo el mundo. Los principios cooperativos son pautas mediante las cuales las cooperativas ponen en práctica sus valores. El que mencionamos en el texto es el tercer principio denominado de "participación económica).

(38) En particular, artículo 46.1 de la Ley $27 / 1999$, de 16 de julio, de Cooperativas.

(39) Artículo 46.1 de la Ley 27/1999, de 16 de julio, de Cooperativas.

(40) Respecto a las cooperativas es sabido que sus normas reguladoras admiten la existencia de socios/as colaboradores estos son "personas físicas o jurídicas, que, sin poder desarrollar o participar en la actividad cooperativizada propia del objeto social de la cooperativa, pueden contribuir a su consecución". Sin embargo, la tajante declaración de la norma sectorial a la que están sometidas las de seguros en virtud del artículo 101 Ley de Cooperativas, no permite que en ellas exista ningún socio que no sea a su vez asegurado. Tampoco parece posible que la cooperativa de seguros pueda realizar la actividad y servicios cooperativizados con terceros no socios como prevé el artículo 4 Ley General de Cooperativas, salvo cuando por "circunstancias excepcionales no imputables a la misma, el operar exclusivamente con sus socios y, en su caso, con terceros dentro de los límites establecidos por esta Ley en atención a la clase de cooperativa de que se trate, suponga una disminución de actividad que ponga en peligro su viabilidad económica", la entidad obtenga la pertinente autorización del Ministerio de Economía y Hacienda para realizar, o, en su caso, ampliar actividades y servicios con terceros, por el plazo y hasta la cuantía que fije la autorización en función de las circunstancias que concurran. 
recae en personas distintas. En la actualidad, la cuestión planteada lo resuelve el artículo 11.1.a) del ROSSP disponiendo que "cuando el tomador del seguro y el asegurado no coincidan en la misma persona, la condición de mutualista la adquirirá el tomador, salvo que en la póliza de seguro expresamente se haga constar que deba serlo el asegurado". Con independencia de valorar la idoneidad de la opción elegida por el reglamento que puede ser fácilmente cuestionada sobre la base de lo expuesto en este trabajo (identidad entre la comunidad de sujetos expuesta al riesgo (p. ej. los asegurados) y la comunidad personal societaria) que avalaría justamente la opción contraria, lo cierto es que no parece correcto que la póliza de seguros sea el documento más adecuado para determinar la excepción a la regla. Por este motivo, nuestra propuesta va en la línea de reconocer que la condición de mutualista/socio sea inseparable de la de asegurado o, alternativamente, que esta norma remita a los estatutos de la sociedad para determinar quién adquiere aquella cualidad cuando asegurado y tomador sean sujetos distintos.

En otro orden de cosas, la diferencia principal de la mutua respecto a las cooperativas de seguros radica en la disociación entre la condición de mutualista y la de aportante del Fondo Mutual como se deriva del propio articulado del TRLOSSP(41). En primer lugar, el artículo 37.2.d), TRLOSSP al señalar que" los mutualistas que hayan realizado aportaciones para constituir el fondo mutual (...)" parece sugerir que no todos los mutualistas han realizado dicha aportación. Más aún, si nos atenemos al estatuto jurídico de los mutualistas recogido en el vigente ROSSP, el artículo 14 ni siquiera menciona la aportación al fondo mutual entre las obligaciones exigibles. En segundo término, el fenómeno de la no vinculación de los socios al Fondo Mutual viene avalado por el derecho a percibir intereses no superiores al interés legal del dinero por su aportación al mismo que se contempla en el artículo 9.2.c) TRLOSSP. Si el socio, por el mero hecho de serlo, tuviera la obligación de efectuar aportaciones al fondo mutual, como ocurre en la Sociedad Anónima o en la Sociedad Cooperativa, no tendría derecho a recibir una remuneración por este motivo en la medida que el pago de intereses viene a cumplir la función de una retribución por el servicio que sólo algunos socios han prestado a la Sociedad y una compensación para equilibrar su situación respecto a los socios no aportantes que, no obstante, se aprovechan de la existencia de dicho Fondo. Por último, el artículo 34 LOSSEAR cuando dispone que "Las mutuas a prima fija deberán acreditar fondos mutuales permanentes, aportados por sus mutualistas o constituidos con excedentes de los ejercicios sociales, (...)" abunda en el hecho que el Fondo Mutual no se forma, como necesariamente ocurre en la Sociedad Anónima o en la Cooperativa, con aportaciones procedentes de los socios.

La desconexión entre la condición de mutualista y de aportante al Fondo Mutual ha llevado a algunos autores ${ }^{(42)}$ a concluir que dicho Fondo constituye una conditio iuris para que las sociedades mutuas obtengan la preceptiva autorización administrativa que les permita el acceso la actividad aseguradora(43) pero en ningún caso un elemento o requisito constitutivo de aquellas. Si esto es así, el Fondo Mutual carece de los rasgos típicos del Capital Social de las sociedades mercantiles (fundamentalmente, sociedades de capital) en su doble vertiente económica y jurídica. La primera considera que el capital se integra con las aportaciones que los socios efectúan para que la sociedad desarrolle las operaciones que constituyen su objeto. Desde esta perspectiva, lo relevante es la acumulación de los medios aportados por los socios a la sociedad cuya contrapartida se refleja en la cuenta de capital social. Como hemos visto, los mutualistas no solo no están obligados a realizar aportación obligatoria al Fondo Mutual sino que dicho Fondo puede nutrirse de otras fuentes (por ejemplo, excedentes).

La segunda connotación es de carácter jurídico y se refiere a la doble función de garantía y organizativa del capital social. Según la primera, el capital expresa la cifra a que debe ascender como mínimo el patrimonio social líquido que lo socios se comprometen a mantener, en el sentido que no podrán retirar cantidad alguna de ese patrimonio ni en concepto de beneficios ni en ningún otro salvo en el caso de reducción de capital siempre que se cumplan los requisitos legales. Esta función tampoco es típicamente característica del Fondo Mutual porque el mutualista puede darse de baja voluntaria en cualquier momento, obteniendo así el reembolso de sus aportaciones ${ }^{(44)}$. De hecho, esta peculiaridad impide la consideración

(41) Así lo entendía también. a propósito de la Ley de 1984, Nicolás Martí, "El fondo mutual en las Sociedades Mutuas de Seguros" en Autores Varios, Edición e introducción de Evelio Verdera y Tuells, Comentarios a la Ley de Ordenación del Seguro Privado, Vol. II, (Madrid, 1988), 445 y siguientes.

(42) Martí, "El fondo mutual en las Sociedades Mutuas de Seguros", en Comentarios a la Ley de Ordenación del Seguro Privado, 445 y siguientes.

(43) El artículo 22 LOSSEAR exige, entre otros requisitos para obtener la autorización administrativa para el acceso a la actividad "disponer del capital social o fondo mutual mínimo y de los fondos propios básicos admisibles para cubrir el mínimo absoluto del capital mínimo obligatorio".

(44) Se trata además de un derecho del mutualista reconocido por el artículo 9.2.f) TRLOSSP. 


\section{El ejercicio de la actividad aseguradora por las empresas de la Economía Social: una revisión crítica de la situación en España}

de las aportaciones al Fondo Mutual como recurso propio ${ }^{(45)}$. Por último, es claro que el Fondo Mutual no cumple la función organizativa del capital social en el sentido de servir como pauta ineludible para las distintas relaciones jurídicas que existen en el interior de la sociedad o entre los socios y la sociedad.

Ahora bien, que el Fondo Mutual no pueda identificarse con el "capital social" de una sociedad mercantil no significa que las sociedades mutuas no precisen de la existencia de un "fondo común" integrado por las aportaciones de los socios. Así parece también considerarlo Martí Sánchez cuando señalaba que son los propios asegurados, quienes a su vez son mutualistas, "Ios primeros interesados en contar con los elementos indispensables para iniciar la actividad aseguradora, en su propio y exclusivo interés"(46). Este "fondo común" constituye un presupuesto ineludiblemente unido a toda figura societaria y la aportación, en tanto en cuanto representa la contribución de cada socio a los medios necesarios para la consecución del fin social, un elemento esencial de todo contrato asociativo. Por este motivo nuestra propuesta va en la línea de proponer la caracterización del Fondo Mutual como un elemento constitutivo de la sociedad mutua y no como una conditio iuris para acceder a la actividad. Cuestión distinta es la cuantía de este Fondo Mutual y si realmente resulta necesario equipararla al exigido para las Sociedades Anónimas. Parece pasar inadvertido el hecho que en los últimos 30 años no se haya constituido ninguna nueva mutua ni se haya materializado ninguna experiencia de aseguramiento cooperativo debido, probablemente a las dificultades para impulsar una iniciativa de este tipo desde y por los consumidores de seguros.

La cuestión de la relación existente entre la cualidad de asegurado y mutualista ha sido analizado por algunos insignes mercantilistas. A propósito del estudio de la Ley de ordenación de 1984, Duque (1988, 367 y siguientes) señalaba que el acceso a la condición de mutualista que se verifica por la vía de la celebración de un contrato de seguro evidencia que "la posición jurídica del mutualista no se agota ni en la sola dimensión societaria ni en la pura relación aseguradora". La doctrina citada por este autor mantiene posiciones extremas entre quienes postulan la prevalencia de una relación sobre la otra, con las subsiguientes prelación de fuentes en caso de conflicto, y quienes defienden que entre ambas relaciones una íntima conexión de tal forma que el contrato de seguros se establece en el contrato social constituyendo un todo económica y jurídicamente unitario ${ }^{(47)}$. Carro del Castillo( ${ }^{(48)}$ mantenía la tesis que:

"para los socios, el contrato de sociedad no es sino un mero instrumento de la finalidad que realmente persiguen, que no es otra que la de verse garantizados de los riesgos que se ven sometidos, estableciendo una comunidad de perdidas, en la que, recíprocamente, todos se comprometen a colaborar en las perdidas ajenas a cambio de ser objeto de igual colaboración en las propias".

Esta afirmación le llevaba a colegir que las mutuas como ente dotado de personalidad jurídica carece de una finalidad propia o autónoma puesto que se crea "con el único objeto de ser instrumento de la operación de seguro en su más primitiva formulación: la unión de muchos con el único fin de ayudarse recíprocamente". Por su parte, Tirado Suárez (2002, 4483 y siguientes) analiza la problemática de la relación entre la condición de socio del mutualista y la condición de parte de un contrato de seguro con la entidad mutual de la que se es socio a lo largo de las distintas normas de ordenación. De esta revisión realizada por el profesor cabe concluir que dichas normas no han mantenido una postura única sino que los aspectos societarios ${ }^{(49)}$ han ido perdiendo peso a favor de los aspectos contractuales ${ }^{(50)}$.

Entrando ya en el estatuto jurídico del socio conviene recordar que como toda persona

(45) Por este motivo, el Real Decreto 1318/2008, de 24 de julio, cuyo objeto era la adecuación del Reglamento de ordenación y supervisión de los seguros privados, al nuevo marco contable aplicable a las entidades aseguradoras en virtud del Real Decreto 1317/2008, de 24 de julio, por el que se aprueba el Plan de contabilidad de las entidades aseguradoras, y a la Ley 16/2007, de 4 de julio, de reforma y adaptación de la legislación mercantil en materia contable para su armonización internacional con base en la normativa de la Unión Europea, propuso una nueva redacción del artículo 59 del ROSSP en la que enunciaba como partida del patrimonio neto no comprometido, "las aportaciones no reintegrables de socios o mutualistas", cuando cumplan los siguientes requisitos:1) Que los estatutos de la entidad prevean que su devolución no ocasione un descenso del patrimonio propio no comprometido por debajo de la cuantía mínima del margen de solvencia y que, en caso de liquidación de la entidad, sólo se harán efectivos después de liquidar todas las demás deudas de la empresa. 2) Que su devolución se notifique a la Dirección General de Seguros y Fondos de Pensiones con un mes de antelación a su pago, pudiendo prohibirlo mediante resolución motivada en el plazo de un mes desde que la Dirección General de Seguros y Fondos de Pensiones tuviera conocimiento de la notificación de la empresa.3) Que las disposiciones de los estatutos, así como sus modificaciones, referentes a esta partida sean aprobadas por la Dirección General de Seguros y Fondos de Pensiones.

(46) Ídem, 478.

(47) Ídem, citando a Gasperoni, 370

(48) Jesús Carro del Castillo, cit. 437 y siguientes

(49) El aspecto societario se destacaba en el Real Decreto de 2 de febrero de 1912 dictado en desarrollo de la primera norma de ordenación de 14 de febrero de 1908 y en la Ley de 1854

(50) Las sucesivas normas de 1984 y 1995, por el contrario, parecen inclinarse por destacar el aspecto contractual. 
jurídica de naturaleza asociativa, cabe distinguir dos planos diferenciados, estos son, el contractual y el corporativo. El contrato de sociedad mutua participa del carácter colaborativo típico de esta modalidad en contraposición con los llamados contratos de cambio en los que cada parte persigue intereses contrapuestos que se satisfacen mediante el estricto cumplimiento de los deberes que a cada una le incumben. Con ello se quiere decir que la cooperación de todos los socios no sólo es imprescindible para la consecución del fin común sino que la satisfacción del interés individual depende de aquel. Esto es especialmente certero en las sociedades mutuas de seguro dado el sempiterno principio de mutualidad económica que implica la existencia de un grupo de sujetos amenazados por riesgos homogéneos que contribuyen recíprocamente a reparar las consecuencias de los siniestros que afecten a una de ellas. De la relación contractual que sirve de base a la sociedad mutua surge una relación entre cada una de las partes contratantes (socios mutualistas) y la propia sociedad instaurando una organización objetivada a la que se someterá el individuo que adquiera la condición de socio y que le atribuirá un determinada posición jurídica, la cual es el presupuesto del conjunto de derechos y obligaciones que configura su estatuto jurídico. Huelga decir que estos derechos y obligaciones son distintos de los que se derivan del contrato de seguro que el socio ha suscrito con la entidad si bien aparecen estrechamente interconectados como tendremos ocasión de apuntar.

Los derechos de los mutualistas se contemplan, por remisión del TRLOSSP(51), en el artículo 13 ROSSP. La norma reglamentaria distingue entre derechos políticos, económicos y de información. Los primeros obedecen a uno de los rasgos rasgo más característico de las mutuas y, en general, de las aseguradoras de la economía social derivada de su calificación como organizaciones democráticas en las que, en el proceso de toma de decisiones, se aplica el principio de "una persona, un voto", independientemente del capital o cotizaciones aportadas por los socios. Ello significa que los socios usuarios de la actividad controlan mayoritaria o exclusivamente el poder de decisión de la empresa. De hecho, el criterio democrático se considera imprescindible para que una empresa sea considerada como integrante de la ES ya que la utilidad social de estas empresas proviene de su propia finalidad y de los valores democráticos y participativos que incorporan en su funcionamiento. EI ROOSP recoge este principio afirmando que:

"[L]os derechos políticos de los mutualistas responderán al principio de igualdad. Cada mutualista tendrá un voto. Todos tendrán las cualidades de elector y elegible para los cargos sociales, siempre que estén al corriente de sus obligaciones sociales, así como el derecho de asistir a las Asambleas generales, formular propuestas y tomar parte en las deliberaciones y votaciones de las mismas, todo ello en la forma que establezcan los estatutos (...)".

Del precepto citado se infiere que el modelo de gobierno democrático de las entidades de la ES implica la participación activa de los socios en los órganos de la sociedad.

Como regla general las aseguradoras de la ES disponen de dos órganos obligatorios: la Asamblea general y el Consejo de Administración, Junta Directiva o Consejo Rector. Adicionalmente, pueden contemplarse otros órganos facultativos u obligatorios en los estatutos o en el propio texto legal. La Asamblea General es la reunión de los socios/mutualistas para deliberar y tomar acuerdos como órgano supremo de expresión de la voluntad social en las materias que le atribuye la ley y su reglamento así como los Estatutos. Junto a esta competencia amplia, que aunque literalmente solo se refiere al debate, debe entenderse comprensiva también de la decisión, las normas reguladoras de los distintos tipos societarios consignan una serie de asuntos de competencia exclusiva de este órgano y por ello absolutamente indelegables bajo pena de nulidad(52). Más allá de esta somera descripción, el ROSSP únicamente menciona qué mayorías serán necesarias para la adopción de acuerdos ${ }^{(53)}$ remitiendo en aspectos tan relevantes como el régimen de convocatoria, o la constitución de este órgano, "a lo dispuesto en la normativa aplicable a las sociedades anónimas, en cuanto no contradiga el régimen específico de esta clase de entidades". Con independencia de cuestionar la idoneidad de esta remisión, no podemos pasar por alto la ironía de la expresión "en cuanto no contradiga el régimen específico de esta clase de entidades" teniendo en cuenta que en realidad no existe tal régimen. Probablemente, el redactor de la norma quiso referirse a la "naturaleza específica de estas entidades" y, si este hubiera sido el caso, el tipo societario más próximo a las mutuas no son las sociedades anónimas, sino las cooperativas por lo que tal vez hubiera sido más adecuada una remisión a la legislación cooperativa.

Lo previsto para la Asamblea General de las Mutuas coincide, en líneas generales, con las

(51) Artículo 9.3 TRLOSSP.

(52) En el caso de las Sociedades Mutuas, el artículo 16.2 ROSSP señala los siguientes: el nombramiento y revocación de los miembros del Consejo de Administración, la aprobación de las cuentas anuales, aprobación de las cuentas anuales y la aplicación del resultado, acordar nuevas aportaciones obligatorias al fondo mutual, modificar los Estatutos sociales, etcétera.

(53) Artículo 17 ROSSP. 


\section{El ejercicio de la actividad aseguradora por las empresas de la Economía Social: una revisión crítica de la situación en España}

previsiones del Reglamento de Mutualidades de Previsión Social (RMPS) para el mismo órgano. Así, el artículo 38 dispone que:

"en lo no previsto expresamente en el presente Reglamento, el régimen de convocatoria, constitución, legitimación para asistir, celebración, derecho de información, adopción e impugnación de acuerdos sociales, de las mutualidades de previsión social se ajustarán a lo previsto en el Reglamento de Ordenación y Supervisión de los Seguros Privados para las mutuas de seguros y, subsidiariamente, a los artículos 93 a 122 de la Ley de Sociedades Anónimas y correlativos preceptos del Reglamento del Registro Mercantil, entendiéndose hechas a la asamblea general y la junta directiva las referencias que en dichas normas se hacen a la junta general y al consejo de administración".

Ciertamente resulta turbador que los "vacíos normativos" tengan que integrarse acudiendo a otra norma que también presenta los mismos "vacíos normativos" en cuanto "al régimen de convocatoria, constitución, legitimación para asistir, celebración, derecho de información, adopción e impugnación de acuerdos sociales" lo que, en última instancia, obliga a acudir al régimen de las sociedades anónimas.

En descargo del redactor del RMPS cabe decir que, como mínimo, tuvo el acierto de intuir aquellos aspectos del régimen de las anónimas que podían causar fricciones con la naturaleza específica de las mutualidades y, por ello, introdujo un segundo párrafo en el artículo $38^{(54)}$ en el que se formulan determinadas previsiones que, aunque incompletas, evidencian mejor que ninguno de nuestros argumentos las dificultades que la remisión al régimen de las sociedades anónimas plantea a las entidades de la ES. El artículo 38 RMPS también incluye una última previsión relativa a la posibilidad de celebrar asambleas por delegados fijando las condiciones y los requisitos de las mismas. Las asambleas por delegados son especialmente convenientes para las aseguradoras de la economía social en atención al elevado número de socios/ mutualistas y, por este motivo, no solo las prevé el RMPS sino también la Ley 27/1999, de 16 de julio, de Cooperativas. Sin embargo tanto el TRLSSOP como el ROSSP guardan silencio sobre esta cuestión respecto a las Mutuas por lo que sería conveniente que una futura norma se pronunciar al respecto máxime si, como señalamos en otro apartado, uno de los retos más importantes de estas sociedades es fomentar la participación de los socios en la asamblea general como órgano que en última instancia ejerce el control de los directivos.

El segundo órgano social obligatorio para las mutuas es el órgano de Administración. Frente a la prolija regulación del mismo en otras normas societarias el ROSSP se limitan a fijar unas escuetas reglas sobre sus competencias ${ }^{(55)}$ y composición. Con relación a este último aspecto, el artículo 18 del ROSSP señala que el Consejo de Administración está integrado "por personas físicas o jurídicas nombradas por la asamblea general que tengan la condición de mutualistas". Esta previsión marca una relevante diferencia no ya con las sociedades anónimas sino también con las sociedades cooperativas puesto que el segundo párrafo del artículo 34 de Ley 27/1999, de 16 de julio, de Cooperativas contempla la posibilidad que, por vía estatutaria se pueda admitir "el nombramiento como consejeros de personas cualificadas y expertas que no ostenten la condición de socios, en número que no exceda de un tercio del total, y que en ningún caso podrán ser nombrados Presidente ni Vicepresidente".

(54) Este segundo párrafo señala que: (...) en el régimen de funcionamiento de la asamblea general previsto en los estatutos de las mutualidades de previsión social se observarán las siguientes peculiaridades: a) Las menciones a la participación en el capital social, sea genéricamente, sea a capital suscrito o a capital desembolsado, se entenderán hechas en todos los casos a número de mutualistas; b) No será necesaria la publicación del anuncio de convocatoria en el Boletín Oficial del Registro Mercantil; c) Entre la primera y la segunda convocatoria deberá mediar, por lo menos, una hora de diferencia, no siendo de aplicación lo dispuesto en el apartado 2 del artículo 98 de la Ley de Sociedades Anónimas; d) Cuando en la convocatoria de la asamblea general figure en el orden del día la adopción de acuerdos que supongan la modificación de los derechos de los mutualistas como asegurados, deberá convocarse individualmente a aquellos mutualistas a los que afecte el acuerdo, debiendo acompañarse junto con la convocatoria el texto de los reglamentos de prestaciones o de los acuerdos que vayan a ser sometidos a aprobación, así como un informe justificativo emitido por la junta directiva. En caso de que los acuerdos que se vayan a adoptar afecten a las expectativas de derechos de un determinado grupo de mutualistas, incluyendo aquellos que hayan pasado a tener la condición de beneficiarios, el acuerdo habrá de adoptarse por la mayoría de los afectados; e) No serán admisibles las limitaciones de los derechos de asistencia y voto recogidas en los artículos 104 y 105 de la Ley de Sociedades Anónimas. Los estatutos sociales contendrán la previsión del modo de acreditar la condición de mutualista con anterioridad a la celebración de la asamblea general; f) Las asambleas generales se celebrarán en la localidad donde la mutualidad tenga su domicilio social, salvo que los estatutos prevean que, por razones justificadas, se puedan celebrar en otro u otros lugares; g) Salvo disposición contraria de los estatutos, los mutualistas podrán hacerse representar en la asamblea general por medio de otra persona, que deberá reunir necesariamente la condición de mutualista. Los estatutos sociales podrán limitar el número de representaciones que pueda tener un mismo mutualista en la asamblea general, que no podrán exceder del $5 \%$ del número total de mutualistas, con un límite máximo de 50.

(55) Los artículos 19 ROSSP y 39 RMPS señalan las siguientes a) Fijar las directrices generales de actuación en la gestión de la sociedad. b) Nombrar los cargos de dirección de la entidad a los que se refiere el art. 40,1 a) de la ley. c) Ejercer el control permanente y directo de la gestión de los cargos de dirección. d) Presentar a la Asamblea General, las cuentas anuales, el informe de gestión y la propuesta de aplicación del resultado. 
Con relación a los derechos económicos primeramente centraremos nuestra atención en el que se refiere al cobro de derramas activas que se acuerden ${ }^{(56)}$. Este peculiar derecho obedece a otra singularidad de las entidades de la ES consistente en la posibilidad de distribuir beneficios o excedentes entre los socios usuarios, pero no en proporción al capital o a las cotizaciones aportadas por los mismos, sino de acuerdo con la actividad que éstos realizan con la entidad. La primera cuestión que debe dilucidarse es cómo se concilia esta circunstancia con la rotunda declaración del artículo 9.2.a) TRLOSSP sobre la ausencia de ánimo de lucro en las sociedades mutuas que se predica también respecto a las mutualidades en virtud de la remisión del artículo 64.3.a). Descartando que la exclusión del ánimo de lucro deba identificarse con una explotación del seguro ajena a criterios empresariales, la razón de ser de esta característica debe rastrearse en el hecho que los integrantes de la comunidad personal societaria sean los mismos que los integrantes de la comunidad de intereses de los asegurados o, lo que es lo mismo, existe identidad entre los productores de los servicios de aseguramiento y los destinatarios de estos servicios. En este sentido ha de entenderse el lucro que se excluye es el que corresponde a la intermediación que realiza el empresario capitalista.

EI TRLOSSP aborda el tema de la aplicación del resultado de las sociedades mutuas en el artículo 9.2.e) con el siguiente tenor:

"Ios resultados de cada ejercicio darán lugar a la correspondiente derrama activa o retorno que, en cuanto proceda de primas no consumidas, no tendrá la consideración de rendimiento del capital mobiliario para los mutualistas o, en su caso, pasiva, que deberá ser individualizada y hecha efectiva en el ejercicio siguiente; o se traspasarán a las cuentas patrimoniales del correspondiente ejercicio".

Es decir, si el resultado ha sido positivo, dará lugar a la correspondiente derrama activa o retorno y, si es negativo, a una derrama pasiva. Respecto a la primera posibilidad, el artículo 11. b) del ROSSP dispone que

"los resultados positivos, una vez constituidas las garantías financieras exigidas por la ley, incluso la reserva a que se refiere el artículo 19 de ésta, se destinarán en primer término a la devolución de las aportaciones reintegrables a socios o mutualistas realizadas para constituir el fondo mutual o a incrementar las reservas patrimoniales, y el exceso sobre dichas cuantías podrá distribuirse entre los mutualistas".

Las normas sobre la aplicación de resultados resultan de aplicación a las mutualidades de previsión en virtud de la remisión efectuada por los artículos del TRLOSSP y 64.3.c) respectivamente.

Del planteamiento legal se deduce que el derecho al cobro de derramas activas se configura de un modo similar al derecho al dividendo en las sociedades de capital. Es decir, el mutualista tiene un derecho abstracto a participar en la distribución de los resultados positivos y un derecho de crédito determinado frente a la sociedad para la entrega de una parte de estos resultados (derrama activa) sólo si la asamblea general de mutualistas acuerda su reparto y en la cuantía que le corresponda que no está en función del capital social desembolsado sino de su participación en la actividad social, esto es, en función de la prima. El problema de este paradigma es que no se cohonesta con el propósito principal subyacente en la mutualización del seguro, este es, contribuir recíprocamente a reparar las consecuencias patrimonialmente adversas que se deriven de la materialización del riesgo al menor coste individual posible. Por consiguiente, los resultados positivos (excedentes) de cada ejercicio deberían redundar directamente en la reducción de la prima. Esta opinión es coincidente con la que mantenía el profesor Duque en sus comentarios sobre este aspecto en la derogada LOSP (Duque 1988, 398); entonces señalaba que:

"en la mutua los excedentes son (...) la diferencia entre el precio de mercado que practican las sociedades anónimas de seguro y que han pagado los mutualistas como contraprestación a la garantía aseguradora y el precio más bajo que la mutua hubiera podido realizar si, conforme a principios rigurosos de la Mutualidad hubiera aplicado un cálculo que eliminara el beneficio que corresponde al empresario".

Ello significa que la diferencia entre estos precios son "adelantos que los mutualistas han hecho a la explotación económica de la mutua y que el desarrollo real o efectivo de los negocios ha puesto de manifiesto que eran innecesarios". Por esta razón concluía que una vez cubiertas las atenciones de la explotación, la mutua debería restituir el excedente a los mutualistas mediante las derramas activas.

Finalmente, otro de los derechos reconocidos a los mutualistas por el artículo 9 TRLOSSP es el participar en la distribución del patrimonio en caso de disolución de la mutua. Este derecho se limita a los mutualistas que integren la mutua en el momento en que se acuerde la disolución y quienes, no perteneciendo a ella en dicho momento, lo hubiesen sido en el período anterior fijado en los estatutos; todo ello sin perjuicio del

(56) Artículo 13.3.b) ROSSP. 


\section{El ejercicio de la actividad aseguradora por las empresas de la Economía Social: una revisión crítica de la situación en España}

derecho que les asiste a los partícipes en el fondo mutual. Con la dicción legal, el proceso de distribución del patrimonio parece quedar supeditado a la previa devolución de las aportaciones al fondo mutual a los mutualistas que hubieran participado en la constitución de dicho fondo bien en el momento constitutivo, bien posteriormente en virtud de un acuerdo de la asamblea general. Dicho de otro modo, el patrimonio que se distribuye es el resultante tras la previa liquidación del fondo mutual. Ello es coherente con la propia configuración legal del fondo y con la disociación entre la condición de mutualista y aportante del fondo mutual si bien una revisión de estos elementos daría lugar a un tratamiento distinto del derecho mencionado.

Por lo que respecta al derecho de información, el ROSSP ofrece un tratamiento muy similar al que prevé la norma que regula las sociedades de capital. Así, el derecho de información puede revestir dos modalidades. Según la primera, contemplada en el artículo 13.5.a) ROSSP, los mutualistas podrán solicitar por escrito, con anterioridad a la celebración de cada Asamblea General o verbalmente durante la misma, los informes o aclaraciones que estimen precisos acerca de los asuntos comprendidos en el orden del día. Los Administradores estarán obligados a proporcionárselos, salvo en los casos en que, a juicio del Presidente, la publicidad de los datos solicitados perjudique los intereses sociales. Esta excepción no procede cuando la solicitud esté apoyada por mutualistas que representen, al menos, la cuarta parte del fondo mutual. Sorprende esta traslación de la LSC máxime si tenemos en cuenta como está configurado actualmente el Fondo Mutual y el hecho que haya mutualistas que no hayan hecho aportaciones a dicho Fondo. En nuestra opinión, el derecho de información es imprescindible para la correcta articulación del principio democrático que caracteriza estas entidades por ello, debería ser regulado con mucha mayor amplitud que en las sociedades capitales, sopesando cuidadosamente las excepciones.

La segunda modalidad se presenta en el contexto de las Asambleas Generales ordinarias y aquellas en cuya convocatoria figure alguna propuesta económica. En este caso, los administradores deben poner a disposición de los mutualistas, en el domicilio social de la mutua, los documentos que reflejen dichas propuestas (o los relativos a las cuentas anuales de la entidad) para que puedan ser examinados por aquellos, en la forma que estatutariamente se establezca, desde la convocatoria hasta la celebración. Asimismo, se reconoce el derecho de los mutualistas a solicitar por escrito al Consejo de Administración las explicaciones o aclaraciones que estimen convenientes para que sean contestadas en el acto de la Asamblea General. Dado que las mutuas pueden agrupar a un número de socios considerable y que estos pueden ubicarse en zonas geográficamente muy alejadas del domicilio social, sería conveniente prever en los Estatutos el envío de esta documentación o su consulta por medios telemáticos adoptando las garantías que correspondan para acreditar la identidad del socio.
Los deberes del mutualista se enuncian en el artículo 14 ROSSP para las mutuas y en el artículo 32. 6 RMPS para las Mutualidades de Previsión Social. Ambos preceptos coinciden en las fuentes de estos deberes, legales y estatutarias, así como en el contenido de los mismos. En primer lugar, destaca el deber de cumplir los acuerdos válidamente adoptados por los órganos de la mutua que debe entenderse similar al previsto para las sociedades de capital. En su momento, el tenor literal de este deber fue considerado como un argumento contrario al reconocimiento del derecho de separación del mutualista en caso de transformación de la mutua; derecho que actualmente reconoce sin ambages el párrafo cuarto del artículo 24.1 TROLSSP. Aún sin la precisión legal, debería entenderse que el carácter vinculante de los acuerdos sociales válidos es decir, aquellos que no sean contrarios a la ley y a los estatutos, debe conciliarse con la protección del socio en situaciones que comportan una profunda modificación de su estatuto jurídico, como ocurre en las modificaciones estructurales y en la cesión de cartera, operaciones todas ellas en las que el legislador español muestra una clara tendencia a favorecer el tránsito a la sociedad anónima desde los tipos societarios de la economía social.

El segundo deber consiste en satisfacer el importe de las derramas pasivas y demás obligaciones económicas estatutariamente establecidas. En efecto, del mismo modo que el mutualista tiene derecho al cobro de derramas activas, en los términos que han sido analizados en otro epígrafe, cuando los resultados son positivos, debe hacer efectiva su responsabilidad si estos resultan negativos. Por este motivo el artículo 11.1.b) ROSSP dispone que las pérdidas sean absorbidas por las derramas pasivas, las reservas patrimoniales y, en último término, por el fondo mutual. Asimismo es imperativo que la derrama se "individualice" y se haga efectiva en el ejercicio siguiente al que se hayan producido los resultados ${ }^{(57)}$. Sobre este particular conviene advertir una cierta discordancia con las previsiones sobre la aplicación de excedentes positivos; si éstos deben destinarse incrementar reservas patrimoniales antes incluso de satisfacer la derrama activa, lo razonable sería que las pérdidas se enjugaran con dichas reservas en

(57) Artículo 9.2.e) TRLOSSP. 
primer lugar y sólo después de acreditada su insuficiencia podría exigirse el pago de derramas pasivas. No sólo porque esta es la función principal de las reservas patrimoniales sino porque, además, ello permitiría un eventual comportamiento oportunista de los administradores y directivos de la entidad contrario a los intereses de los mutualistas.

Un dato fundamental es que el incumplimiento de este deber lleva asociado la sanción prevista en la letra c) del artículo 11.1 ROSSP consistente en la baja del mutualista, una vez transcurridos sesenta días naturales desde que hubiera sido requerido fehacientemente para el pago. Esta baja que en principio implica la pérdida de la condición de socio, deja temporalmente subsistente el contrato de seguro hasta el próximo vencimiento del período de seguro en curso, momento en el cual quedará definitivamente extinguido. Se trata de una previsión que no sólo protege al asegurado en cuanto tal sino también al resto de mutualistas por lo que convendría extender su aplicación a todos aquellos supuestos en los que se constate el incumplimiento del mutualista por una causa distinta a la falta de pago de las derramas pasivas.

Finalmente hay que señalar que a pesar de la pérdida de la condición de socio, subsiste su responsabilidad por las obligaciones contraídas por la mutua con anterioridad a la fecha en que la baja produzca efecto. En línea de principio, la responsabilidad de los socios está limitada a un importe igual al de la prima que anualmente pague, circunstancia que debe destacarse en las pólizas de seguro.

\section{Conclusiones}

El somero análisis de las entidades aseguradoras de la ES confirma la conclusión que el legislador español sigue sin acoger las especificidades de estas fórmulas societarias hasta sus últimas consecuencias y muestra una clara tendencia a favorecer su aproximación al tipo dominante: el de las sociedades de capital. Esta circunstancia, además de provocar las incoherencias y lagunas que han sido comentadas, plantea una profunda contradicción con la defensa y promoción de la Economía Social y de sus principales operadores. Es por ello que, en la elaboración de cualquier norma futura o en la revisión de las vigentes, deberían tenerse en cuenta las reflexiones y sugerencias que seguidamente expondremos.

Con relación a la normativa sectorial de ordenación, supervisión y solvencia de las entidades de seguros, es necesario postular una apreciación más purista del principio de proporcionalidad para aquilatar la exigencia de determinados requerimientos, particularmente los relativos al gobierno corporativo, cuando éstos se proyectan sobre entidades de la economía social. El principio de proporcionalidad no solo es un pilar configurador de la acción de la $U^{(58)}$ sino que también aparece expresamente recogido, entre otros, en el Considerando (19) la Directiva 2009/138/CE, del Parlamento Europeo y del Consejo, de 25 de noviembre de 2009, sobre el seguro de vida, el acceso a la actividad de seguro y de reaseguro y su ejercicio (Directiva Solvencia II) afirmando que su aplicación no debe "resultar demasiado gravosa para las pequeñas y medianas empresas de seguros". En nuestra opinión no se trata solo de una cuestión de "tamaño de la empresa" sino también de "naturaleza del empresario" por lo que habría sido deseable que la Directiva hubiera dado un paso más incluyendo en el universo de entidades beneficiarias de este "principio de proporcionalidad" a las integrantes de la ES.

A nivel interno, sugerimos que el legislador español admita la cooperativa de seguros de trabajo asociado, y no sólo la de consumo, como fórmula apta para el ejercicio de la actividad aseguradora. Así lo recomienda el "Informe sobre la Economía Social" aprobado por la Comisión de Economía y Hacienda del Congreso de los Diputados en 2011 y se constata en el interés demostrado por algunos colectivos profesionales por constituir este tipo de cooperativas. Asimismo, la existencia de una norma específica permite aconsejar que la LOSSEAR se limite a los aspectos puramente técnicos derivados del ejercicio de la actividad aseguradora tal y como ya ocurre con la sociedad anónima. Resulta del todo punto reprobable que la norma de ordenación, supervisión y solvencia efectúe continuas e injustificadas remisiones a disposiciones distintas de las normas sobre cooperativas o, lo que es peor, pretenda introducir modificaciones al régimen jurídico de estas sociedades que no vengan justificados por razones técnicas. A título de ejemplo, pueden admitirse limitaciones en la distribución de excedentes pero no un régimen distinto de distribución al previsto en la normativa específica sobre cooperativas.

Con respecto a las Mutuas y Mutualidades de Previsión Social, se aconseja elaborar una norma de rango legal que articule de forma

(58) El Apartado 4 del artículo 5 del TUE recoge literalmente lo siguiente: "En virtud del principio de proporcionalidad, el contenido y la forma de la acción de la Unión no excederán de lo necesario para alcanzar los objetivos de los Tratados. Las instituciones de la Unión aplicarán el principio de proporcionalidad de conformidad con el Protocolo sobre la aplicación de los principios de subsidiariedad y proporcionalidad". Los criterios concretos para su aplicación se encuentran en el Protocolo $n^{\circ} 2$ sobre la aplicación de los principios de subsidiariedad y proporcionalidad anexo al Tratado de la Unión Europea y al Tratado de Funcionamiento de la Unión Europea. 
unitaria y completa el régimen societario de estas entidades sobre la base de su consideración como un único tipo social si bien con distintas posibilidades operativas.

Finalmente, y en línea con las principales políticas de la UE, como el Acta del Mercado Único ${ }^{(59)}$ que confirman lo que hemos venido afirmando en este trabajo, "para poder desarrollarse y responder a sus objetivos, el sector de la economía social en el mercado interior deberá poder adoptar unas formas de organización dotadas de un estatuto jurídico especial", entendemos que el verdadero reto para el legislador comunitario y nacional estriba en asumir que este estatuto jurídico especial debe impregnar el marco jurídico y reglamentario en todos sus ámbitos, desde el derecho sociedades hasta la política de empresa, pasando por el derecho contable, fiscal, armonización estadística, etc. Sólo así, podrá lograrse una cabal articulación de las características de los diferentes operadores que actúan en el mercado y preservar su diversidad(60).

\section{Referencias bibliográficas}

Alfonso Sánchez, Rosalía. 2010. "Algunas consideraciones sobre en torno a la propuesta de Ley 'Marco' de Economía Social”, REVESCO 102.

Bercovitz, Alberto y Broseta, Manuel. 1986. "Consideraciones sobre la naturaleza jurídica de las mutuas de seguros", Revista Española de Seguros 46.

Carro del Castillo, José Antonio. 1986. "Naturaleza jurídica de las mutuas de seguros". Comentarios a la Ley de Ordenación del Seguro Privado, Madrid.

DiMaggio P.J y Powell W. 1983. "The iron cage revisited institutional isomorphism and collective rationality in organizational fields". American Sociological Review 48.

Duque, Justino F. 1988. "Mutuas y Cooperativas en la nueva legislación". Comentarios a la Ley de Ordenación del Seguro Privado. Madrid.
García-Gutiérrez Fernández, Carlos. 1995. "Las sociedades cooperativas de derecho y las de hecho con arreglo a los valores y a los principios del Congreso de la Alianza Cooperativa Internacional de Manchester en 1996: Especial referencia a las sociedades de responsabilidad limitada reguladas en España". REVESCO 61

Garcia Companys, Anna. 2018. "El principio de proporcionalidad en la normativa de gobierno corporativo de las cooperativas de crédito", Comunicación aceptada y presentada en el XVII Congreso Internacional de Investigadores en Economía Social y Cooperativa, con el lema "La Economía Social: transformaciones recientes, tendencias y retos de futuro" celebrado los días 4 y 5 de octubre de 2018.

Garrido Comas, Juan José. 1960. Ensayo para una teoría de la mutualidad. Barcelona.

Garrigues, Joaquín. 1982. Teoría general del contrato de seguros terrestres. Madrid.

Martí, Nicolás. 1988. "El fondo mutual en las Sociedades Mutuas de Seguros" en AA.VV (Edición e introducción de Evelio Verdera y Tuells), Comentarios a la Ley de Ordenación del Seguro Privado, Vol. II.

Merino Merchán, José Fernando. 1979. "Consideraciones generales sobre el cooperativismo de seguros en España”, Revista de Derecho Mercantil 151.

Monzón Ramos, José Luis. 1995. "Las cooperativa de trabajo asociado ante la Reforma de los Principios Cooperativos". REVESCO 61 (ejemplar dedicado a La identidad cooperativa).

Moreno, Rafael y Domínguez, Inmaculada. 2002. "Sociedades Cooperativas de Seguros" en Libro Blanco de las Sociedades Cooperativas y Laborales de Extremadura, Junta de Extremadura, Consejería de Trabajo.

Núñez Lozano, Carmen. 1998. Ordenación y Supervisión de los Seguros Privados. Marcial Pons.

Paz Canalejo, Narciso. 1982. "Las cooperativas de seguros". Revista Española de Seguros 29.

Pérez de Uralde, José María. 2017. "Aplicación, desarrollo y reforma de la Ley 5/2011 de Economía Social. ¿Un derecho debilitado?", REVESCO. Revista de Estudios Cooperativos 125, 134-158.

Puyalto Franco, María José. 1999. La cooperativización de los seguros agrarios. Barcelona.

Tirado Suarez, Francisco Javier. 2002. "La relación mutualistaasegurado en el derecho del seguro vigente", Derecho de sociedades: libro homenaje al profesor Fernando Sánchez Calero. Vol. 4.

(59) Comunicación de la Comisión al Parlamento Europeo, al Consejo, Al comité Económico Social Europeo y al Comité de las Regiones. Acta del Mercado Único. Doce prioridades para estimular el crecimiento y reforzar la confianza "Juntos por un nuevo crecimiento". Bruselas, 13 de abril, COM (2011) 206 final.

(60) En particular, el Acta del Mercado Único se refería a las mutuas para advertir que a pesar de su presencia en sectores fundamentales para los ciudadanos (salud, banca, seguros, etc.), "es poco frecuente que ofrezcan sus servicios en varios Estados miembros; y, sin embargo, con el $25 \%$ del mercado de los seguros y el $70 \%$ del número total de empresas del sector, no pueden ser ignoradas por el mercado único". 